\title{
Determination of parameters of a viscous-cohesive fracture model by inverse analysis
}

\section{Determinação de parâmetros de um modelo visco-coesivo de fratura por análise inversa}
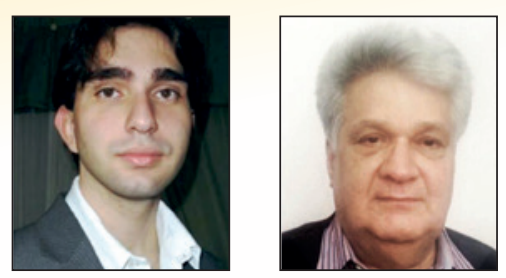

F. L. GEA DOS SANTOS a fabiogea@hotmail.com

J. L. A. O. SOUSA a jls@fec.unicamp.br

\begin{abstract}
The quasi-brittle, loading rate dependent behaviour of the concrete, characterized by a fracture process zone (FPZ) ahead of the crack front, can be described through a viscous-cohesive model. In this paper, a viscous cohesive model proposed in a former paper is evaluated for a group of high strength concrete beams loaded at rates from $10-5 \mathrm{~mm} / \mathrm{s}$ to $10+1 \mathrm{~mm} / \mathrm{s}$. A software has been developed to enable the automatic determination of the viscous-cohesive model parameters through inverse analysis on load-versus loading-point displacement $(\mathrm{P}-\delta)$ from threepoint bend tests on notched prismatic specimens. The strategy allowed the sensitivity analysis of the parameters related to viscous behaviour. The analysis of results shows that the formerly proposed model can be improved for a better simulation of the loading rate dependence on the cohesive fracture process.
\end{abstract}

Keywords: fracture, viscous-cohesive model, inverse analysis.

\section{Resumo}

O comportamento quase-frágil, dependente da taxa de carregamento do concreto, caracterizado pelo desenvolvimento de uma zona de processos de fratura (ZPF) ao redor do fronte da trinca, pode ser representado por uma lei visco-coesiva. Neste trabalho, um modelo visco-coesivo proposto em um artigo anterior foi avaliado para um grupo de vigas de concreto de alta resistência carregados com taxas variando de $10-5 \mathrm{~mm} / \mathrm{s}$ a $10+1 \mathrm{~mm} / \mathrm{s}$. Desenvolveu-se um software para a determinação automática dos parâmetros do modelo visco-coesivo utilizando-se curvas da relação carga versus deslocamento no ponto de aplicação $(P-)$ obtidas em ensaios com vigas prismáticas ranhuradas carregadas em três pontos (Three-Point-Bend Test), com taxas de carregamento variadas. A estratégia permitiu a análise de sensibilidade dos parâmetros relacionados com o comportamento viscoso. A análise dos resultados demonstrou que o modelo visco-coesivo proposto no artigo ainda pode ser aperfeiçoado para melhor simular o processo de fraturamento coesivo dependente da taxa de carregamento.

Palavras-chave: fratura, modelo visco-coesivo, análise inversa. 


\section{Introduction}

Concrete is a material with low tensile resistance. Many internal micro defects and microcracks exist even before any loading is applied. Microcracks depend on many parameters, including particle size distribution, aggregate size, cement content, water/cement ratio, degree of compaction in fresh state, curing conditions, humidity and heat history of concrete. The mechanical behaviour of concrete subject to different loading conditions is governed by the initiation and propagation of these internal microcracks throughout the loading process.

When a concrete structure is subjected to an external load, it may be assumed that, to a certain level of loading, the material exhibits a linear behavior. As the loading increases, the maximum stress is reached in points on the most demanded cross-sections. However, due to the heterogeneous microstructure of the concrete, yield and fracture zones are developed, due to the initiation of microcracks. These zones are concentrated in small volumes adjacent to the most stressed points, which are characterized by a residual ability to transfer stresses.

The ability to transmit stresses through the cracks generated in the concrete can be explained by the persistence of some micro connections between the faces. Figure 1 shows a concrete body subjected to uniaxial tension. As soon as the concrete reaches its tensile resistance $\left(f_{t c}\right)$, cracks are generated, macroscopically indicating that the faces are separated. However, microscopically,

Figure 1 - Representation of the softening process between the crack faces in concrete
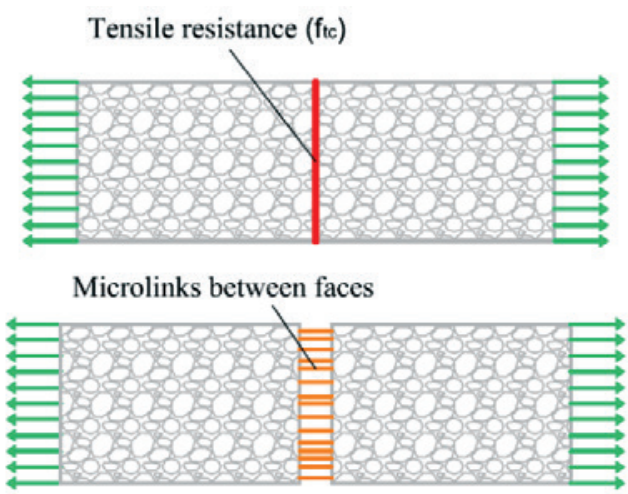

Microlinks reduction with increase of opening between faces

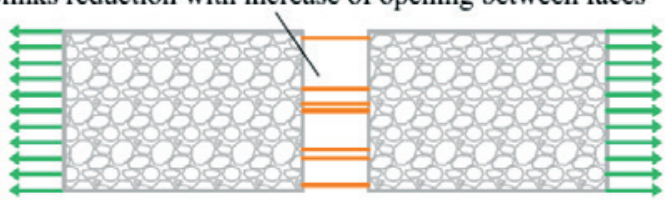

Complete separation between faces
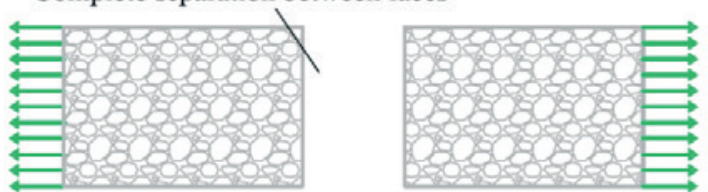

there are still micro connections between the crack faces, which have not reached the tensile strength and continue to contribute to the transmission of stresses between the faces. As the distances between the crack faces increase, micro connections reach the tensile strength, progressively reducing the transmission of stresses between the faces.

Different approaches have been proposed to represent the inelastic process zone and/or fracture process zone (FPZ). Among these, the following may be cited: the fictitious crack model (FCM, [2-4]), the crack band model [5], the two-parameter fracture model [6], the effective crack model [7] and the peak load method [8].

According to the MFF, the FPZ is represented by a discrete (fictitious) fracture whose softening effects are expressed by active cohesive forces between its faces. Figure 2 presents a description of the FCM. In this figure, $w$ is the aperture between the fracture faces, $w_{c}$ is the critical aperture, from which the fracture faces are completely separated, and $f_{t c}$ is the concrete tensile strength.

Besides $f_{t c}$ and $w_{c}$ aforementioned, other property of the cohesive curve is the apparent fracture energy $\left(G_{F}\right)$ corresponding to the amount of energy per unit area required for the complete separation of the two fracture faces. The $G_{F}$ value corresponds to the area under the cohesive curve. Figure 3 shows an example of a cohesive curve.

With the increase in the number of researches on concrete, it was found that it presented a different behavior according to the experimental loading rate. Some examples [9-11] approach the states of compression, traction and bending under different speeds. Despite the considerable amount of research on the subject [12-22], the process resulting from the effect of loading rate on fracture propagation is still unknown.

Based on observations from experimental data with different loading rates, many numerical models have been proposed to adequately represent the role of loading rate in frac-

\section{Figure 2 - Modeling of cohesive crack}

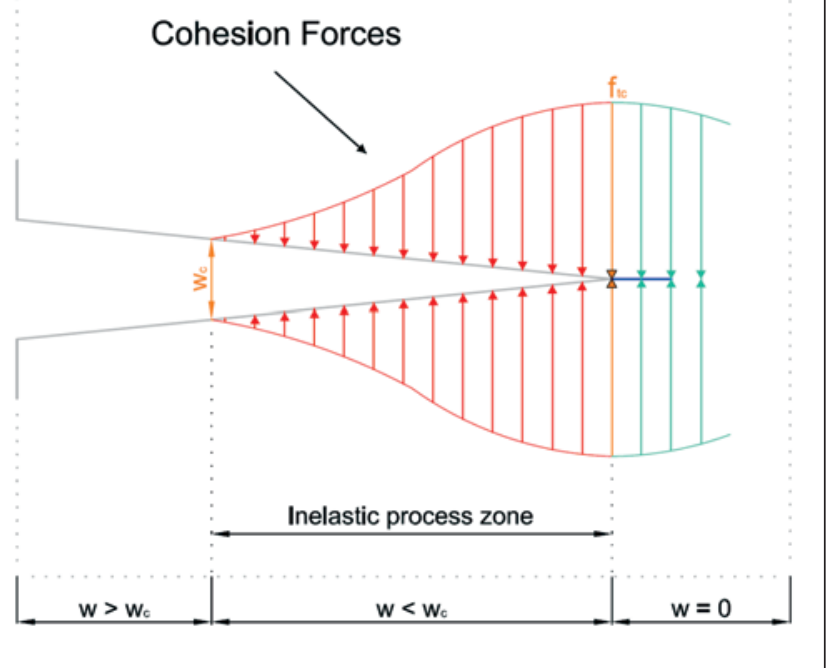




\section{Figure 3 - Example of cohesive curve and its properties}

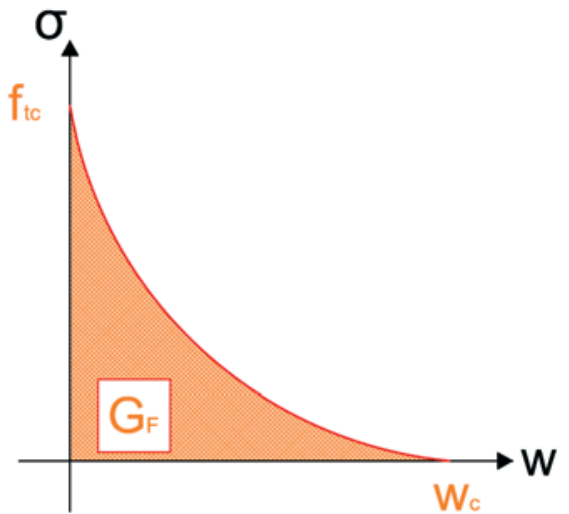

ture propagation in concrete. Most of the proposed models suggest a change in the cohesive curve based on fracture opening rate.

According to Bazant et al. [19], models based on rheology are not sufficient for modelling the influence of the loading rate in the response of material fracture. It suggests the inclusion of parameters related to the viscous behavior of the cohesive crack model. Tandon et al. [23] proposed the following viscouscohesive model:

$$
\mathcal{F}(w, \dot{w})=f(w)+\Psi(\dot{w})
$$

Figure 4 - Behaviour of the viscous parameter proposed by (23)

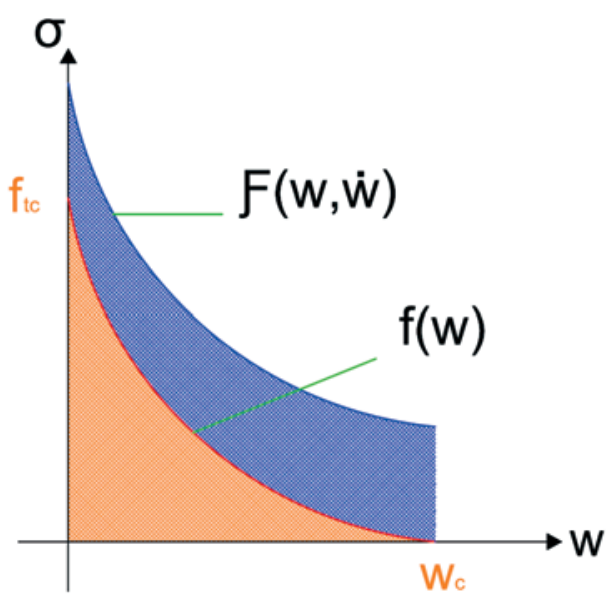

where $\dot{w}$ is the fracture opening speed, $f(w)$ is the static cohesive model and $\varnothing$ is the proposed viscous model:

$$
\Psi(\dot{w})=f_{t c} k \sin ^{-1}\left(\frac{\dot{w}}{\dot{w}_{0}}\right)
$$

The parameters $k$ and $\dot{w}_{0}$ are auxiliary, where the first is dimensionless and the second is a reference speed. The model proposed by [23] makes a positive translation of cohesive curve, as presented in Figure 4. As can also be seen in this figure, the model does not propose any extension of $w_{c}$, presenting a discontinuity in $w_{c}$. Zhou et al. [24] proposed the following model in studies of polymethylmethacrylate (a quasi-brittle material):

$$
\mathcal{F}(w, \dot{w})=f(w, \mathrm{Z}(\dot{w}))
$$

where $f(w, Z(\dot{w}))$ is the formulating of the cohesive curve modified by a factor $Z(\dot{w})$ governed by the following formulation:

$$
\mathrm{Z}(\dot{w})=1+\left(\frac{\dot{w}}{\dot{w}_{0}}\right)^{n}
$$

The parameters $n$ e $\dot{w}_{0}$ are auxiliary, where the first is dimensionless and second a reference speed. The proposed model extends the cohesive curve towards $w$, as shown in Figure 5 . This model expands $w_{c}$, and this factor must be properly assigned, depending on the formulation of cohesive zone model. Further details on the influence of $\mathrm{Z}(\dot{w})$ in $f(w, Z(\dot{w}))$ can be found in [24] and [25].

\section{Figure 5 - Behaviour of the viscous parameter proposed by (24)}

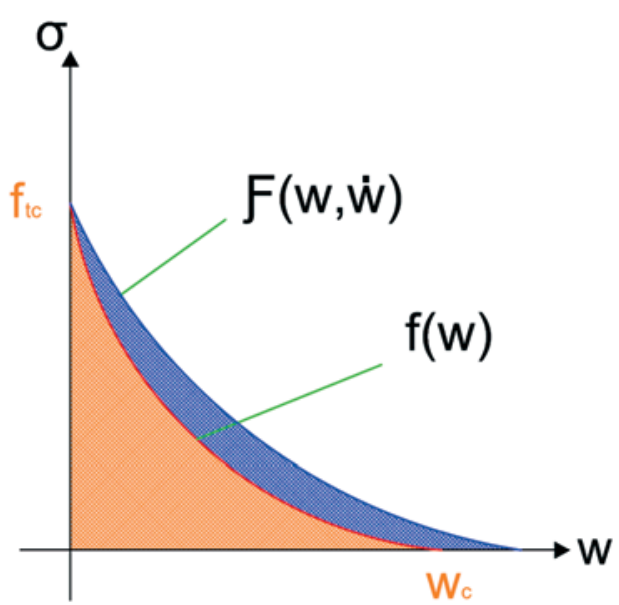




\section{Figure 6 - Behaviour of the viscous parameter proposed by (1)}

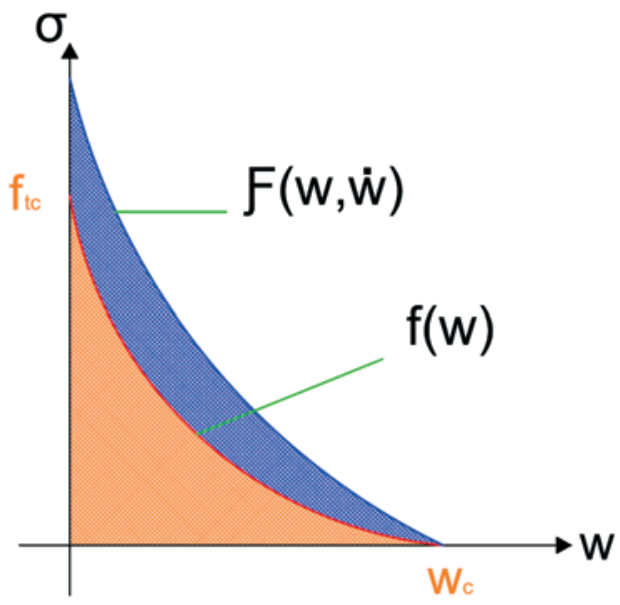

Rosa et al. [1] proposed another viscous-cohesive model using the same factor proposed by Zhou et al. [2] but focusing on the value of cohesion stress:

$$
\mathcal{F}(w, \dot{w})=\mathrm{R}(\dot{w}) \cdot f(w)
$$

The viscous model $R$ proposed is identical to Equation 4, with the difference that this model generates an expansion of cohesive curve towards $\sigma$. This viscous-cohesive model is shown in Figure 6.

\section{1,1 Motivation}

The parameters proposed by the models do not have specific experimental tests, therefore inverse analyses is applied to adjust them. In the work [1], bending tests were performed in a threepoint setup on high resistance concrete beams with speeds ranging from $1.74 \times 10^{-5} \mathrm{~mm} / \mathrm{s}$ to $1.74 \times 10^{+1} \mathrm{~mm} / \mathrm{s}$. The parameters of the viscous model were adjusted using the peak load values in $\mathrm{P}-\delta$ curve (load versus displacement of the load application point), obtained by a finite element model. The study used the proposed bilinear cohesive curve [26], built with experimental test data and represents well the peak of the P- $\delta$ curves.

This paper uses a numerical method for the simultaneous adjustment of the viscous-cohesive parameters. The objective is to evaluate the ability of the viscous-cohesive model [1] to represent the behaviour of concrete under the influence of the loading rate, using a computational tool for adjusting $\mathrm{P}-\delta$ curves obtained in experiments with prismatic beams in three-point bending. The representation capacity of numerical $\mathrm{P}-\delta$ curve with respect to the experimental curves and the correspondence of parameters describing the cohesive curve $\left(f_{t c}\right.$ e $\left.G_{F}\right)$ compared to the values obtained experimentally are used as an evaluation criteria.

\section{Materials}

The test data presented in [1] are used. The experiments were performed on high strength concrete beams subjected to three point bending with the following actuation piston speeds : $1.74 \times 10^{-5} \mathrm{~mm} / \mathrm{s}, 5.5 \times 10^{-4} \mathrm{~mm} / \mathrm{s}, \quad 1.74 \times 10^{-2} \mathrm{~mm} / \mathrm{s}$, $5.5 \times 10^{-1} \mathrm{~mm} / \mathrm{s}$ e $1.74 \times 10^{+1} \mathrm{~mm} / \mathrm{s}$.

The concrete properties were obtained by axial compression tests (Elasticity Modulus, $E_{c}=33.9 \mathrm{GPa}$ ), diametral compression test $\left(f_{t c}=5.2 \mathrm{MPa}\right)$ and three-point-bending tests $\left(G_{F}=123 \mathrm{~J} / \mathrm{m}^{2}\right)$.

\section{Computational tool developed}

A program in $\mathrm{C}++$ has been developed in order to automate the process of inverse analysis and determine the parameters of the viscous model proposed by [1]. This program was based on the idea presented in [27].

The program, called FIT3PB-FG, is divided in two modules: a first module that only adjusts the cohesive parameters and a second module that adjusts viscous and cohesive parameters, i.e. a purely static modulus and other including loading rate dependence. A graphic interface was developed to facilitate the use, display the input data and the solution.

The input data provided by the user are:

The beam's geometry: length $(L)$, span $\left(S_{p}\right)$, height $(h)$, width ( $\left.w_{v}\right)$, notch height $\left(a_{0}\right)$ and modulus of elasticity $\left(E_{c}\right)$ (Figure 7);

- A data file containing the experimental curves. In the case of viscous-cohesive fitting, the experimental curves are divided into groups according to the loading rate.

After data entry, the user must choose among the program options:

- The cohesive model (linear, bilinear, exponential...);

- The viscous model (for example, [1]);

- The numerical model for simulation of $P-\delta$ curve;

- The inverse analisys method.

The FIT3PB-FG performs inverse analysis minimizing the following function:

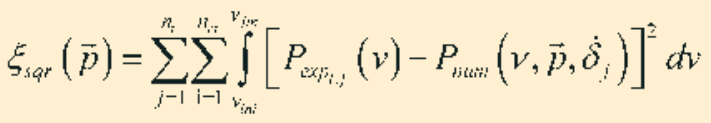

where $n_{t}$ is the number of different loading rates, $n_{e t}$ is the number of specimens tested with a specific loading rate, $P_{\exp }$ is the

\section{Figure 7 - Scheme of the beam in three-point-} bending indicating the geometric dimensions

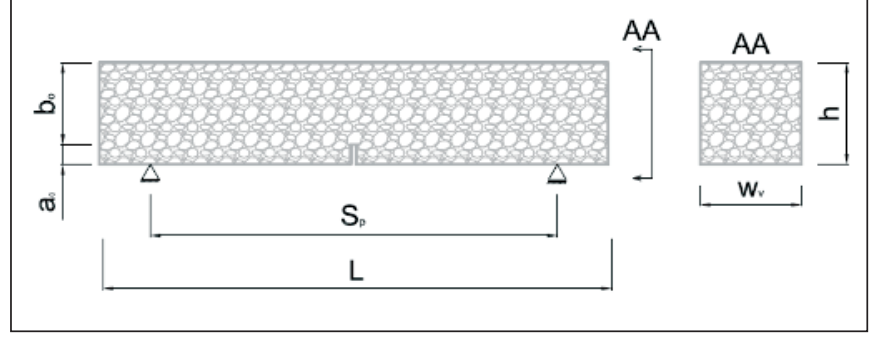




\section{Table 1 - Elasticity modulus results obtained by the program}

\begin{tabular}{ccccc} 
& $\begin{array}{c}\text { Rosa et al. } \\
(2012)(1)\end{array}$ & CHM & SF \\
\hline$E_{c}(\mathrm{MPa})$ & 33900 & 33900 & 33987 \\
$\begin{array}{c}\text { Residue } \\
(\mathrm{KN} \text { '.mm) }\end{array}$ & - & $1.16 \times 10^{-6}$ & $1.23 \times 10^{-6}$ \\
PD (\%) & - & 0.00 & 0.26
\end{tabular}

PD - percent difference relative to the experimental value.

function representing the experimental data, $P_{\text {num }}$ is the function representing the numeric answer, $v$ is a displacement value of the loading point application, $\vec{p}$ is the parameters vector parameters to be adjust and $\dot{\delta}$ is the loading rate.

In the version of FIT3PB-FG used in this study, the existing minimization algorithm is the Levenberg-Marquardt [28-29], whose procedure can also be found in [30].

The numerical models used in the simulation of $\mathrm{P}-\delta$ curves are:

Cracked Hinge Model (CHM) [31]: semi-analytical formulation for the propagation of the fracture in a beam. The basic idea is to model a zone where the fracture propagates with spring elements. These spring elements are connected to rigid edges that bind to the rest of beam.

- Superposition Fracture Model (SF) [32]: It uses the superposition of the Linear Elastic Fracture to represent the answer in Nonlinear Fracture Mechanics. The procedure allows for flexibility with a large number of calculations, since it obtains an optimized system of equations whose resolution requires no inversion of the coefficient matrix.

\section{Metodology}

Based on the set of experimental curves presented by Rosa et al. (2012) [1], the following procedures are performed:

Elastic Modulus Fit: with the tool developed, the elastic modulus is fitted using the numerical models presented in section 3 .

Use of three adjustment ranges: [1] only used the peak of the $P-\delta$ curves as parameter for adjusting the viscous model. To check the influence of the adjustment range in the solution, three intervals of $\delta$ are use:

-0 to $0.45 \mathrm{~mm}$;

-0 to $0.225 \mathrm{~mm}$;

-0 to $0.11 \mathrm{~mm}$ : the end of the range is located just after the peak load of experimental curves, this is the case that is closest to the fit by the curve peak generated by [1];

- Fit of the viscous model using the Bilinear curve shown in [1]: Bilinear curve constructed by [1] is used as cohesive base model to adjust the viscous model. The results are compared to numerical models ( $\mathrm{CHM}$ and $\mathrm{SF}$ ) in the various setting ranges and with reference results.

- Cohesive model fit using the quasi-static experimental data: tests performed with the lowest load rate, $\dot{\delta}=1.74 \times 10^{-5} \mathrm{~mm} / \mathrm{s}$, are considered quasi-static tests. These data sets are used to adjust the cohesive curves of Hordijk [33] and Bilinear. The results are compared with the bilinear curve shown in [1];

Viscous model fitting using the numerically determined cohesive curves: using the cohesive curves from de previous fitting, the viscous model is adjusted based on other experimental tests, corresponding to higher loading rates. The results are compared with the numerical models ( $\mathrm{CHM}$ and $\mathrm{SF}$ ) in different fitting ranges and with the reference results;

- Viscous-cohesive model fit: the viscous and cohesive model (Hordijk or bilinear) are simultaneously fit based on the entire experimental data set at different fitting ranges. The results are compared with the reference data [1];

\section{Results and discussion}

This section presents the results obtained from the procedures described in section 4, accompanied by a comparative analysis in relation to the experimental values and the results presented in [1].

\subsection{Modulus of elasticity fit}

Table 1 shows the results of the elastic modulus fitted using the $\mathrm{CHM}$ and SF model. As can be seen, both models, CHM and SF resulted very close to the modulus of elasticity determined experimentally.

Table 2 - Results obtained by inverse analysis of the model (1) using the bilinear curve

\begin{tabular}{|c|c|c|c|c|}
\hline Model & $\delta_{\max }(\mathrm{mm})$ & $\dot{w}_{0}(\mathrm{~mm} / \mathrm{s})$ & $\mathrm{n}$ & $\begin{array}{l}\text { Residue } \\
\left(\mathrm{kN}^{2} \cdot \mathrm{mm}\right)\end{array}$ \\
\hline \multirow{3}{*}{$\mathrm{CHM}$} & 0.450 & 45.5 & 0.148 & $2.15 \times 10^{-3}$ \\
\hline & 0.225 & 12.3 & 0.137 & $4.51 \times 10^{-4}$ \\
\hline & 0.110 & 10.2 & 0.160 & $9.23 \times 10^{-5}$ \\
\hline \multirow{3}{*}{ SF } & 0.450 & 1.95 & 0.125 & $2.14 \times 10^{-3}$ \\
\hline & 0.225 & 0.497 & 0.111 & $4.32 \times 10^{-4}$ \\
\hline & 0.110 & 0.804 & 0.124 & $9.06 \times 10^{-5}$ \\
\hline Rosa et al. (2012) (1) & 0.450 & 0.0965 & 0.16 & $4.14 \times 10^{-3}$ \\
\hline
\end{tabular}




\section{Figure 8 - Fit P- $\delta$ curve for the range of 0 to $0.45 \mathrm{~mm}$ using bilinear curve (1)}

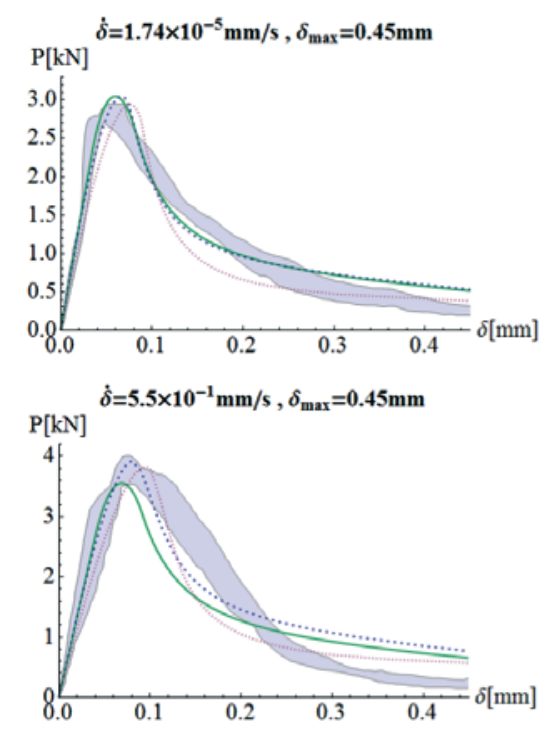

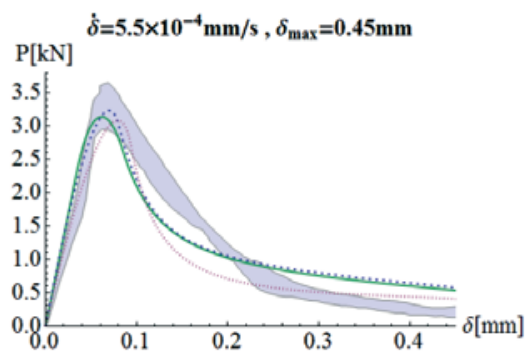

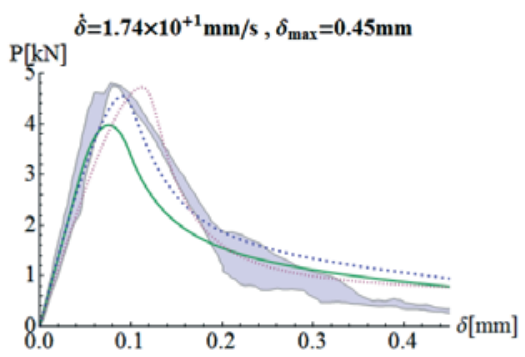

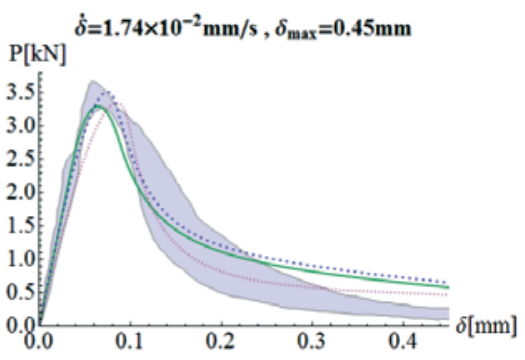

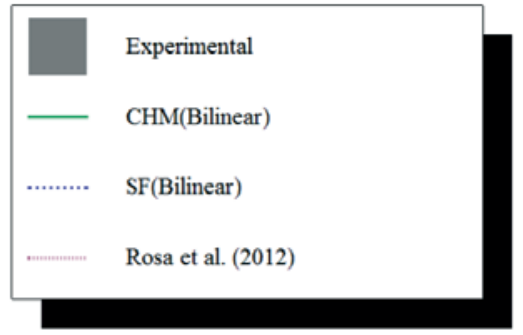

\subsection{Fitting of the viscous model using the bilinear curve shown in [1]}

Table 2 shows the results of the fits, where $\delta_{\max }$ is the maximum value used in the fit. As can be seen, the $\dot{w}_{0}$ parameter differ substantially from interval to interval, and does not correspond to the parameter obtained by [1] even when $\delta_{\max }=0.11 \mathrm{~mm}$. However, full correspondence between the values obtained with $\delta_{\max }=0.11 \mathrm{~mm}$ and obtained by [1] was not expected, since these were obtained through a manual process, interrupted when the resulting curve was considered satisfactory.

Figures 8 to 10 show a graphical comparison between the numerical curves and the experimental envelope. Figure 8 shows that the fitting between the experimental and numerical curves is not satisfactory. This is because the bilinear curve determined in [1]

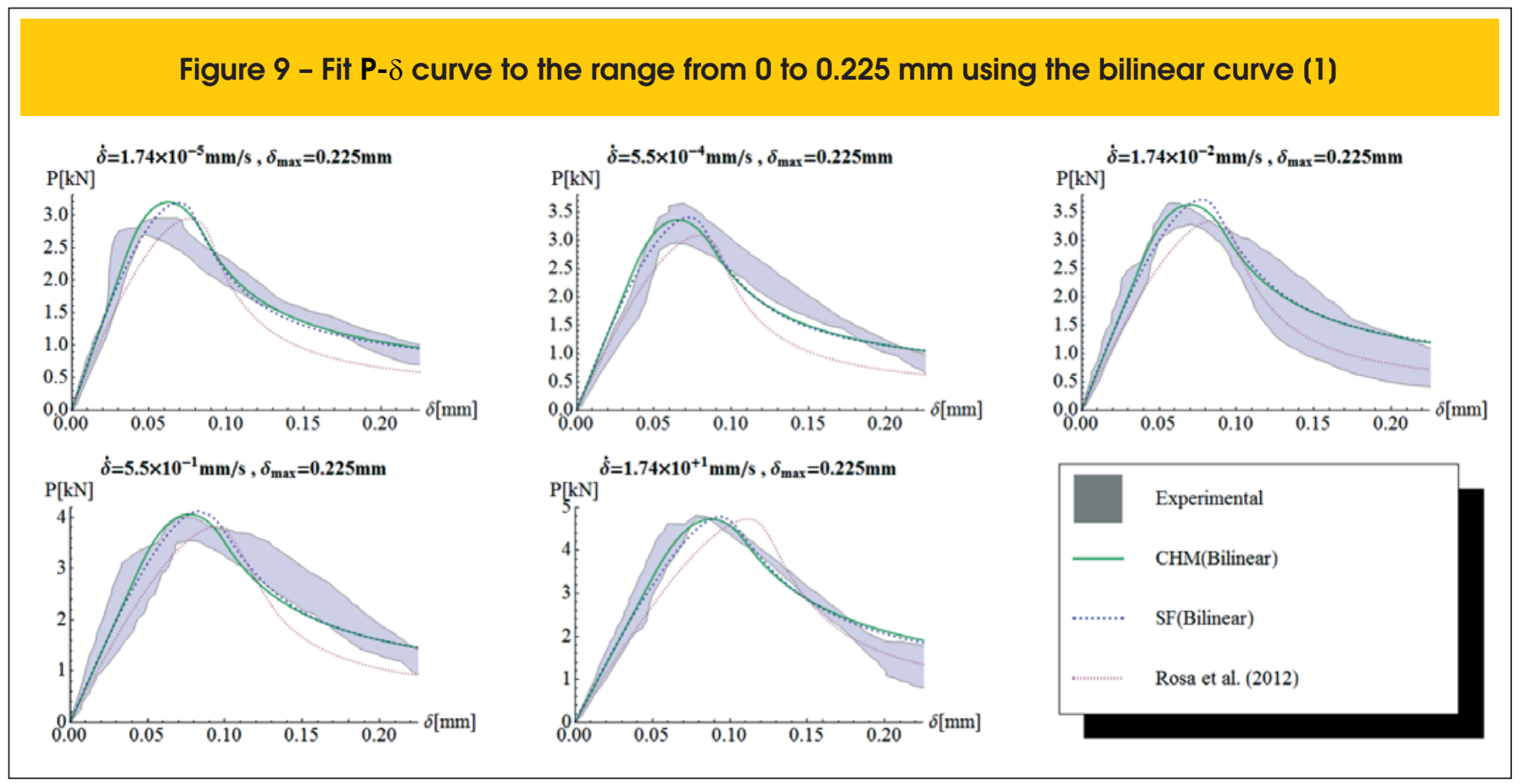




\section{Figure $10-$ Fit $\mathrm{P}-\delta$ curve to the range from 0 to $0.11 \mathrm{~mm}$ using the bilinear curve (1)}
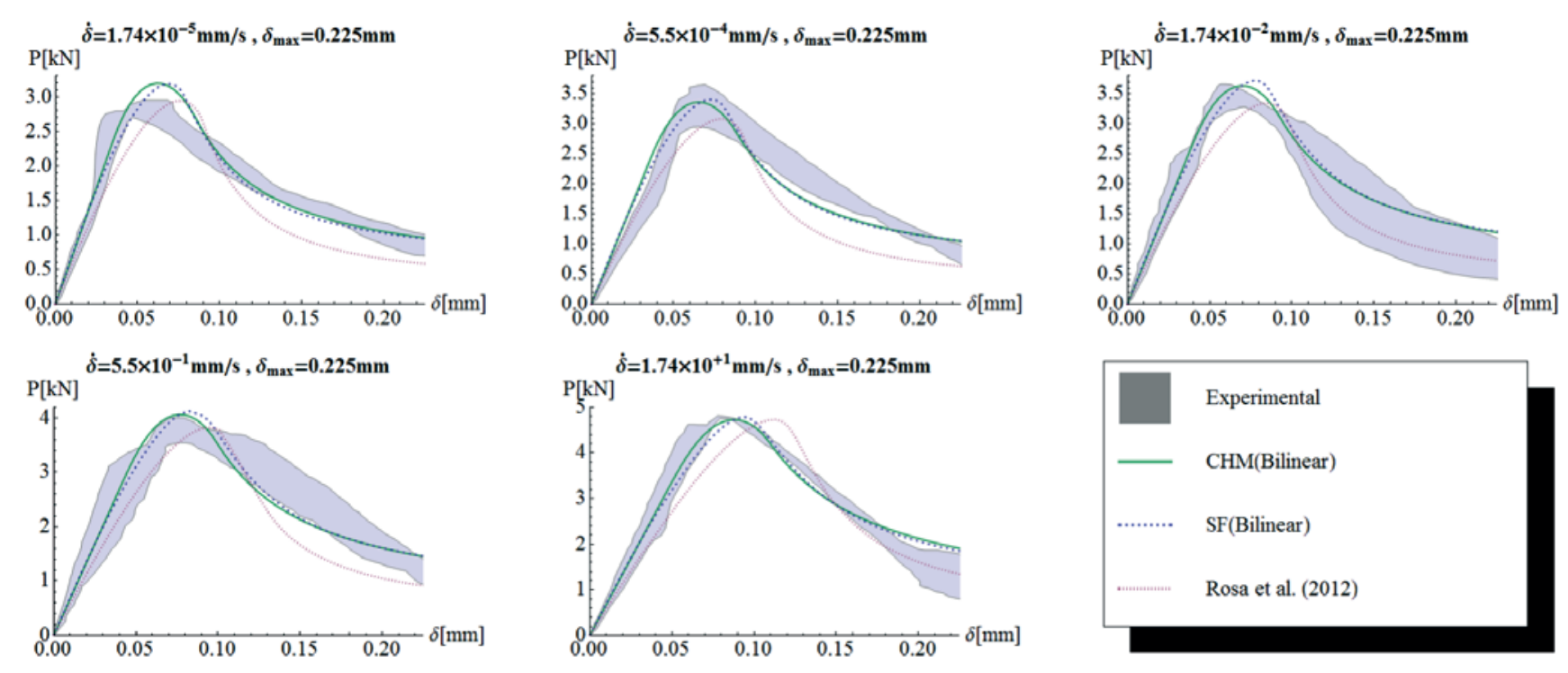

using process [26] is limited to representing the maximum value $P$ of the $P-\delta$ curve (experimental). As can be understood in Figures 9 and 10 the numerical curves are best fitted to experimental data, however, the parameters $n$ and $\dot{w}_{0}$, differ between $\delta_{\max }$ values range.

\subsection{Cohesive model fit using the quasi-static experimental data}

Table 3 shows the results of the fitting on the cohesive curves using the quasi-static experimental envelopes $\left(\dot{\delta}=1.74 \times 10^{-5} \mathrm{~mm} / \mathrm{s}\right)$. Table 4 presents a comparison between numerical and experimental parameters $f_{t c}$ and $G_{F}$. For $G_{F}$ was considered also the comparison of the apparent fracture energy until the experimental data range limit $(0.45 \mathrm{~mm})$ and this values was indicated by $G_{F 0-0,45}$. The results were similar to the experimental values.

The Figures 11 and 12 show the comparison of numerical and experimental $P-\delta$ curves. The fitted curves are satisfactory representations of the behavior of the experimental curves. It can be seen that the main difference of cohesive models set for the bilinear model used in [1] is the value of $w_{c}$, and the set has a value close to $0,10 \mathrm{~mm}$ while in the reference [1] it is above of $0.25 \mathrm{~mm}$.

\subsection{Viscous model fitting using the numerically determined cohesive curves}

Table 5 shows the results of the viscous model using the cohesive curves determined in Section 5.3 and the experimental samples relating to $\dot{\delta}$ rates higher than $1.74 \times 10^{-5} \mathrm{~mm} / \mathrm{s}$. Again, the parameters present a significant variation between ranges.

Figures 13 to 18 show the comparison of fit $P-\delta$ curves with the experimental curves. The numerical model does not represent the experimental peak for $\dot{\delta}=1.74 \times 10^{1} \mathrm{~mm} / \mathrm{s}$. However, these fittings are better than the ones in Section 5.2, because the end of the $\mathrm{P}-\delta$ curve is well represented.

\section{Table 3 - Results of cohesive curves obtained by inverse analysis of the quasi-static envelopes}

\begin{tabular}{|c|c|c|c|c|c|c|c|}
\hline Model & Cohesive & $\begin{array}{c}\mathrm{f}_{\mathrm{tc}} \\
(\mathrm{MPa})\end{array}$ & $\begin{array}{c}G_{F} \\
\left(J / m^{2}\right)\end{array}$ & $\begin{array}{c}a_{1} \\
\left(m^{-1}\right)\end{array}$ & $\underset{\left(\mathrm{mm}^{-1}\right)}{a_{2}}$ & $b_{2}$ & $\begin{array}{c}\text { Residue } \\
\left(\times 10^{-5}\right) \\
\left(\mathrm{kN}^{2} \cdot \mathrm{mm}\right)\end{array}$ \\
\hline \multirow{2}{*}{$\mathrm{CHM}$} & Hordijk & 5.03 & 98 & - & - & - & 5.82 \\
\hline & Bilinear & 4.80 & 100 & 40.3 & 3.16 & 0.30 & 5.92 \\
\hline \multirow{2}{*}{ SF } & Hordijk & 4.78 & 111 & - & - & - & 6.93 \\
\hline & Bilinear & 5.25 & 113 & 49.3 & 3.05 & 0.317 & 6.14 \\
\hline $\begin{array}{l}\text { Rosa et al. } \\
(2012)(1)\end{array}$ & Bilinear & 5.20 & 128 & 50.0 & 0.43 & 0.12 & 414 \\
\hline
\end{tabular}


Table 4 - Comparison of parameters fit with the experimental values

\begin{tabular}{|c|c|c|c|c|c|}
\hline Numerical model & Cohesive model & $\begin{array}{c}f_{\mathrm{fc}} \\
(\mathrm{M} P \mathrm{P})\end{array}$ & $\begin{array}{l}P D f_{t c} \\
(\%)\end{array}$ & $\begin{array}{c}G_{F}\left(G_{F(0-0.045)}\right) \\
\left(J / m^{2}\right)\end{array}$ & $\begin{array}{c}P D G_{F}\left(G_{F(0-0.45)}\right) \\
(\%)\end{array}$ \\
\hline Experimental & - & 5.20 & - & $123(95)$ & - \\
\hline \multirow{2}{*}{$\mathrm{CHM}$} & Hordijk & 5.03 & -2.27 & 98 & $-20.33(3.16)$ \\
\hline & Bilinear & 4.80 & -7.69 & 100 & $-18.70(5.26)$ \\
\hline \multirow{2}{*}{ SF } & Hordijk & 4.78 & -8.08 & 111 & $-9.76(16.84)$ \\
\hline & Bilinear & 5.25 & 0.96 & 113 & $-8.13(18.95)$ \\
\hline
\end{tabular}

\subsection{Viscous-cohesive model fitting}

Tables 6 to 9 show the results obtained by the simultaneous fitting of the viscous and cohesive curves with model [1]. Tables 6 and 8 show that the parameters vary significantly between the fitting intervals. In Tables 7 and 9 there is a significant difference between the numerical parameters and the corresponding experimental results. Figures 19 to 24 show the comparison between the numerical $\mathrm{P}-\delta$ curves and the experimental envelopes. These were the best fit obtained using the viscous model [1].

\subsection{Discussion}

The model [1] was proposed and evaluated for the peak values of the $P-\delta$ curves. The results presented in subsection 5.5 demonstrate that although being a good first approximation, the model [1] shows limitations in the representation of the $P-\delta$ curve. The parameters $f_{t c}$ and $G_{F}$ obtained by simultaneous adjustment of the viscous and cohesive models indicated the need to change the model for a better representation of the experimental values for the loading rates under consideration.

The analysis of quasi-brittle materials and ductile in impact tests raises a question: many materials that exhibit quasi-brittle or ductile behavior when subjected to static loading may have brittle behavior

\section{Figure 11 - Comparison of P- $\delta$ curve obtained by fit of Hordijk (1991) (33) cohesive model}
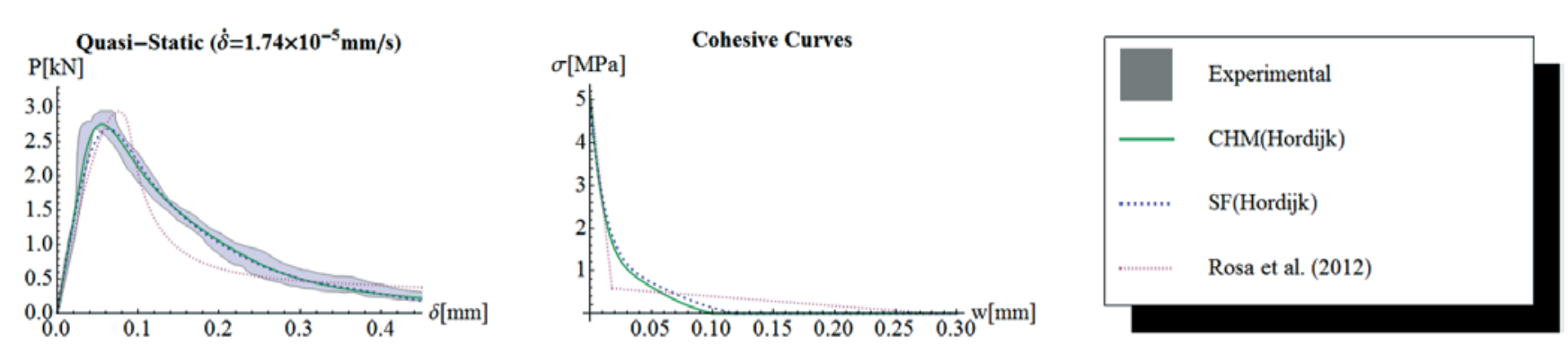

Figure 12 - Comparison of $\mathrm{P}-\delta$ curve obtained by fit of bilinear cohesive model
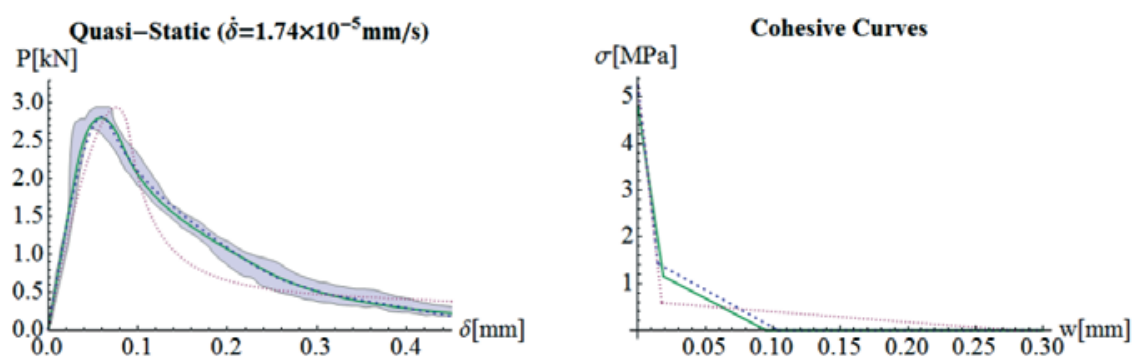

Experimental

CHM(Bilinear)

SF(Bilinear)

Rosa et al. (2012) 


\section{Table 5 - Results obtained by inverse analysis of the viscous model (1) using the cohesive curves numerically determined in Section $\mathbf{5 . 3}$}

\begin{tabular}{|c|c|c|c|c|c|}
\hline Model & Cohesive & $\delta_{\max }(\mathrm{mm})$ & $\dot{w}_{0}(\mathrm{~mm} / \mathrm{s})$ & $\mathrm{n}$ & $\begin{array}{l}\text { Residue } \\
\left(\mathrm{kN}^{2} \cdot \mathrm{mm}\right)\end{array}$ \\
\hline \multirow{6}{*}{$\mathrm{CHM}$} & \multirow{3}{*}{ Hordijk } & 0.450 & 99.0 & 0.156 & $1.25 \times 10^{-3}$ \\
\hline & & 0.225 & 45.0 & 0.152 & $4.42 \times 10^{-4}$ \\
\hline & & 0.110 & 7.74 & 0.161 & $7.38 \times 10^{-5}$ \\
\hline & \multirow{3}{*}{ Bilinear } & 0.450 & 90.3 & 0.154 & $1.29 \times 10^{-3}$ \\
\hline & & 0.225 & 35.2 & 0.152 & $4.39 \times 10^{-4}$ \\
\hline & & 0.110 & 9.32 & 0.16 & $7.32 \times 10^{-5}$ \\
\hline \multirow{6}{*}{ SF } & \multirow{3}{*}{ Hordijk } & 0.450 & 21.3 & 0.158 & $1.15 \times 10^{-3}$ \\
\hline & & 0.225 & 15.6 & 0.149 & $4.45 \times 10^{-4}$ \\
\hline & & 0.110 & 1.55 & 0.159 & $8.04 \times 10^{-5}$ \\
\hline & \multirow{3}{*}{ Bilinear } & 0.450 & 21.6 & 0.167 & $1.22 \times 10^{-3}$ \\
\hline & & 0.225 & 14.7 & 0.156 & $4.63 \times 10^{-4}$ \\
\hline & & 0.110 & 2.29 & 0.148 & $7.27 \times 10^{-5}$ \\
\hline $\begin{array}{l}\text { Rosa et al. (2012) } \\
\text { (1) }\end{array}$ & Bilinear & 0.450 & 0.0965 & 0.16 & $4.14 \times 10^{-3}$ \\
\hline
\end{tabular}

under impact loading. This behavior is due to the impossibility of redistribution of stresses over a very short period of strain [34]. The experiments discussed in [1] do not achieve speeds that can be considered close to an impact, but considering that the material undergoes a gradual transition from a static loading stage to an impact stage, it can be assumed that the material becomes increasingly fragile.

In order to observe the increase in the fragility of the material and check the increase in $f_{t c}$ with an increased loading rate, individual fit is performed for each of the envelope experiments performed

\section{Figure 13 - Fit $P$ - $\delta$ curve for the range of 0 to $0.45 \mathrm{~mm}$ using Hordijk (1991) (33) curve set in section 5.3}
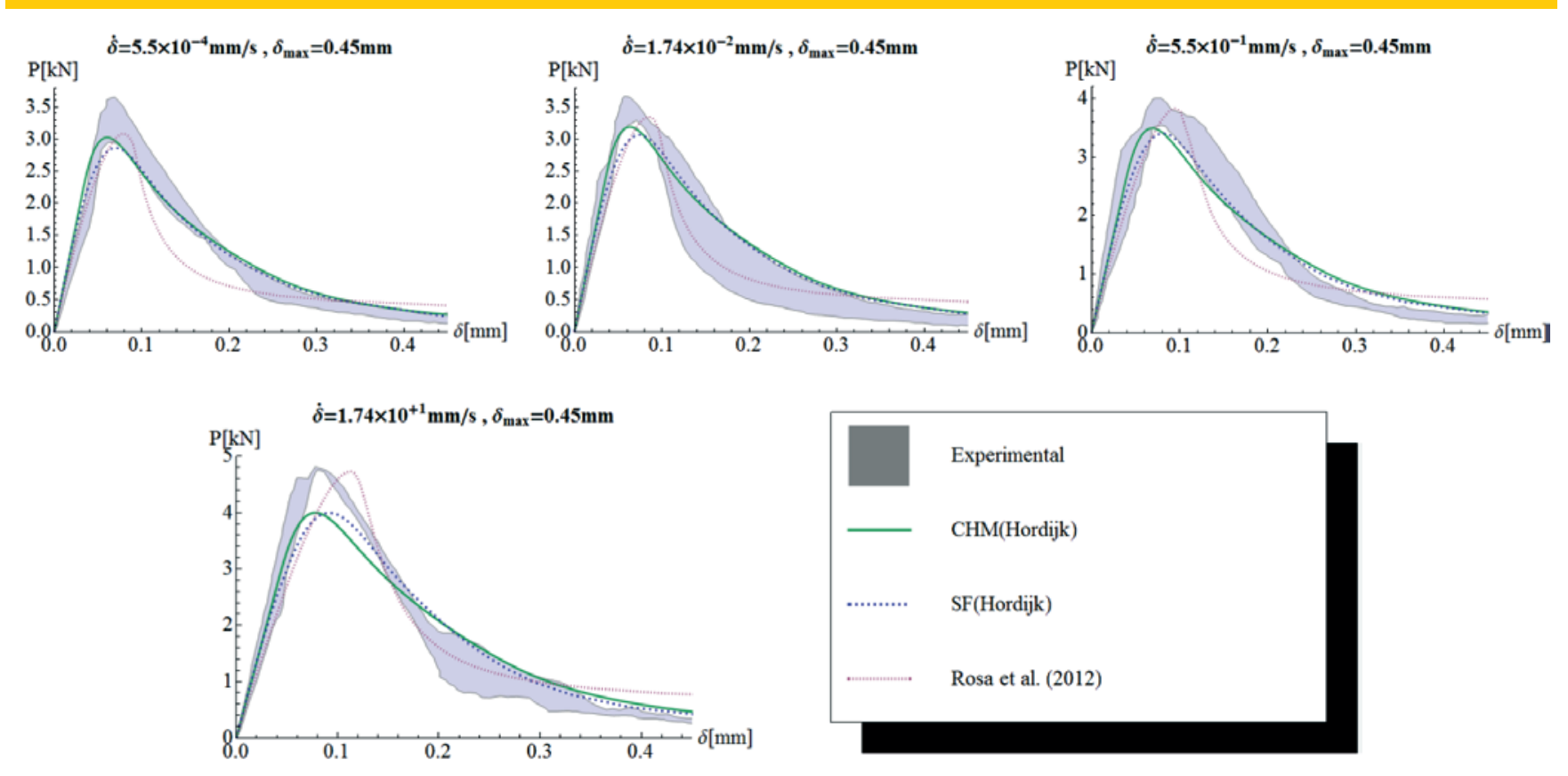


\section{Figure 14 - Fit P- $\delta$ curve for the range of 0 to $0.225 \mathrm{~mm}$ using Hordijk (1991) (33) curve set in section 5.3}
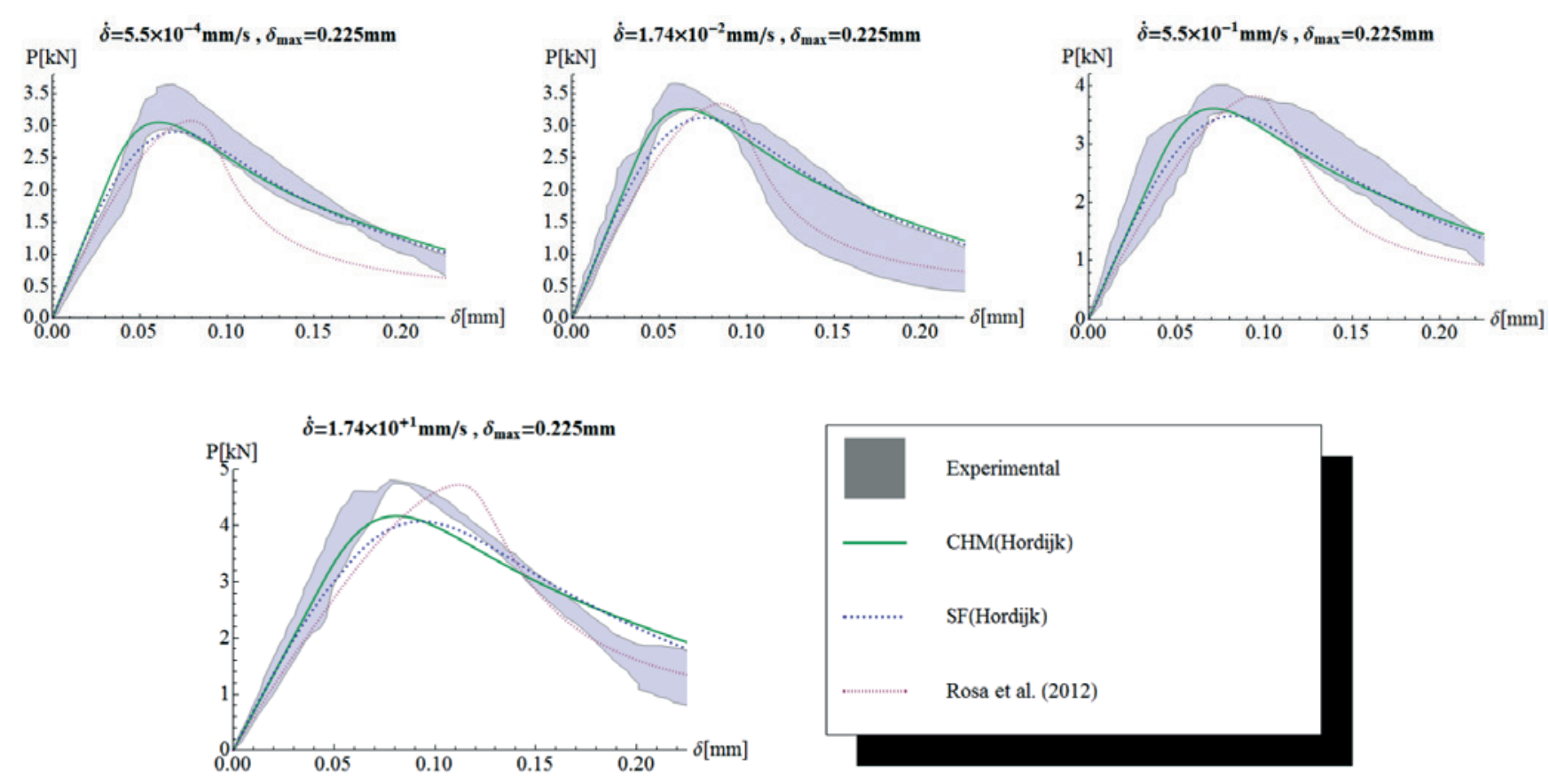

\section{Figure 15 - Fit P- $\delta$ curve for the range of 0 to $0.11 \mathrm{~mm}$ using Hordijk (1991) (33) curve set in section 5.3}
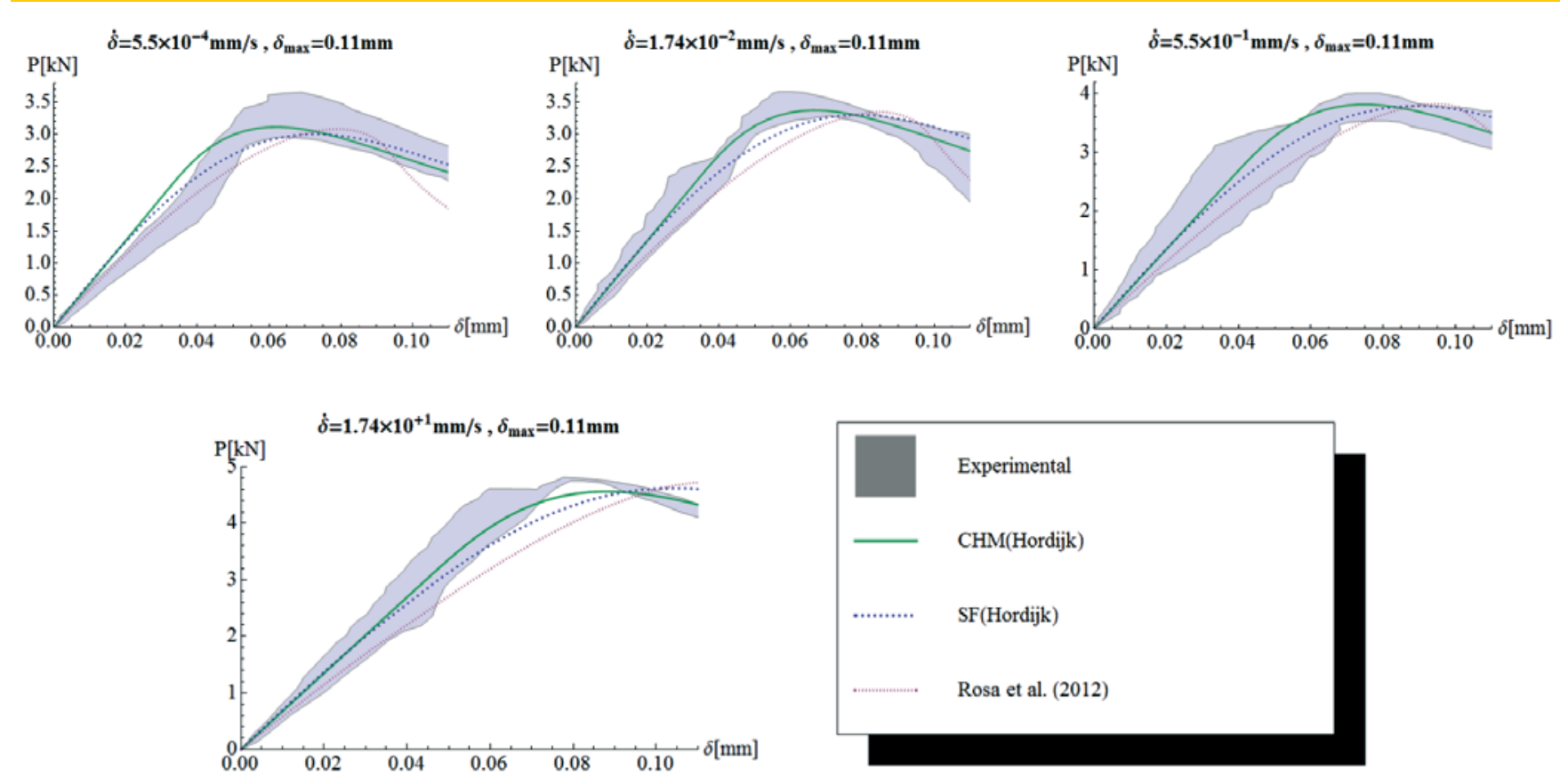


\section{Figure 16 - Fit P- $\delta$ curve for the range of 0 to $0.45 \mathrm{~mm}$ using bilinear curve set in section 5.3}
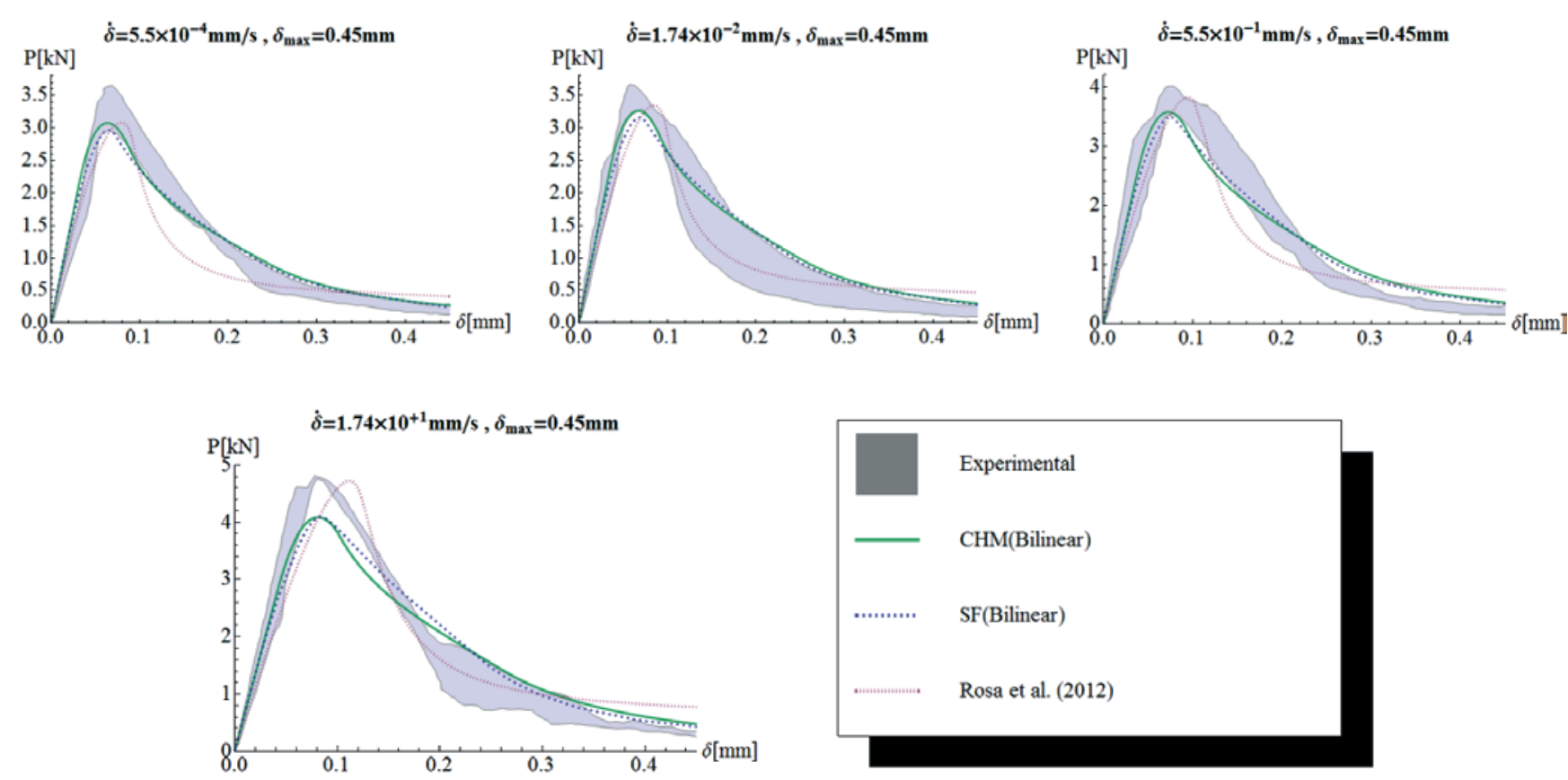

Figure 17 - Fit P- $\delta$ curve for the range of 0 to $0.225 \mathrm{~mm}$ using bilinear curve set in section 5.3
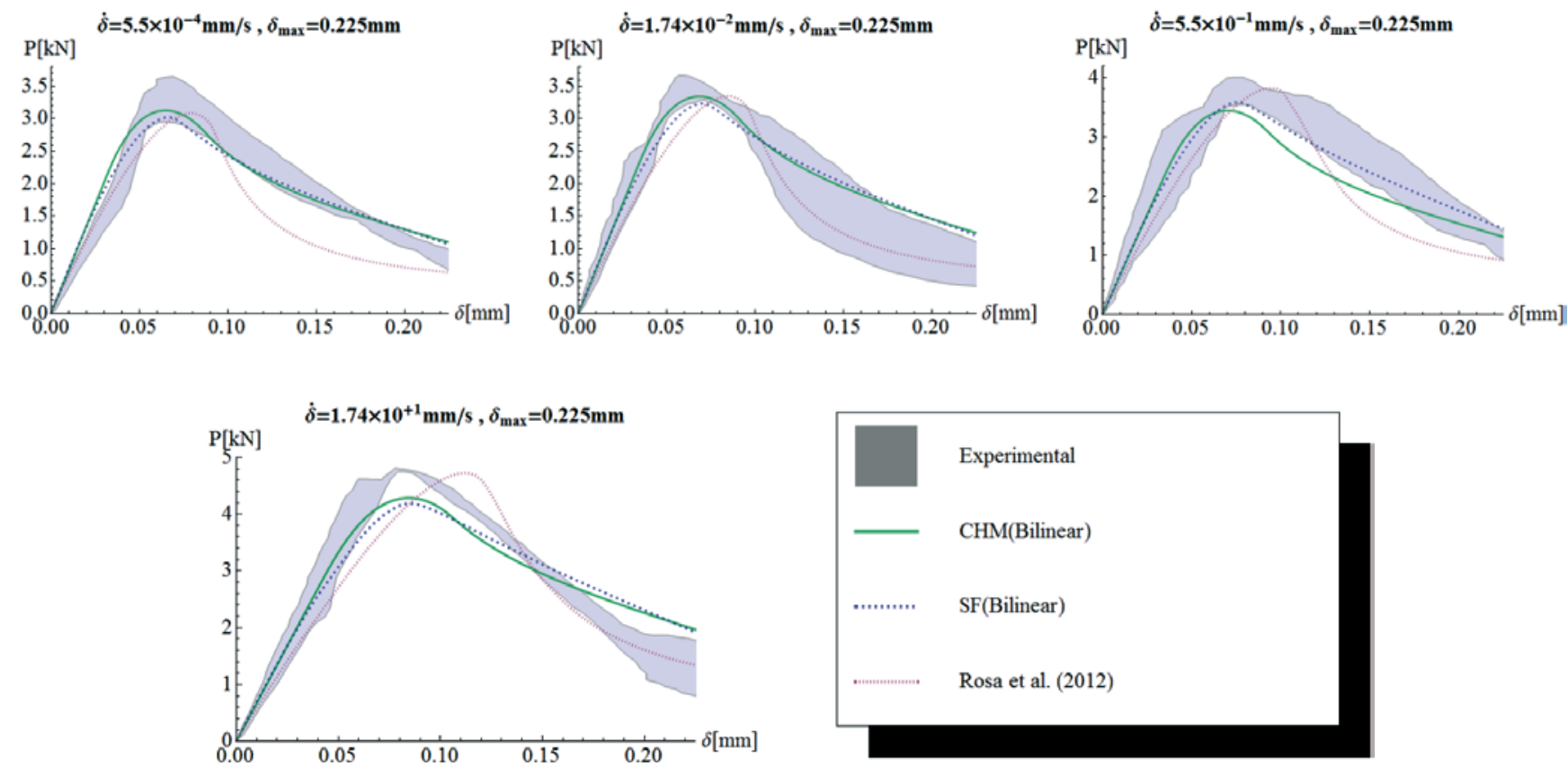


\section{Figure 18 - Fit P- $\delta$ curve for the range of 0 to $0.11 \mathrm{~mm}$ using bilinear curve set in section 5.3}
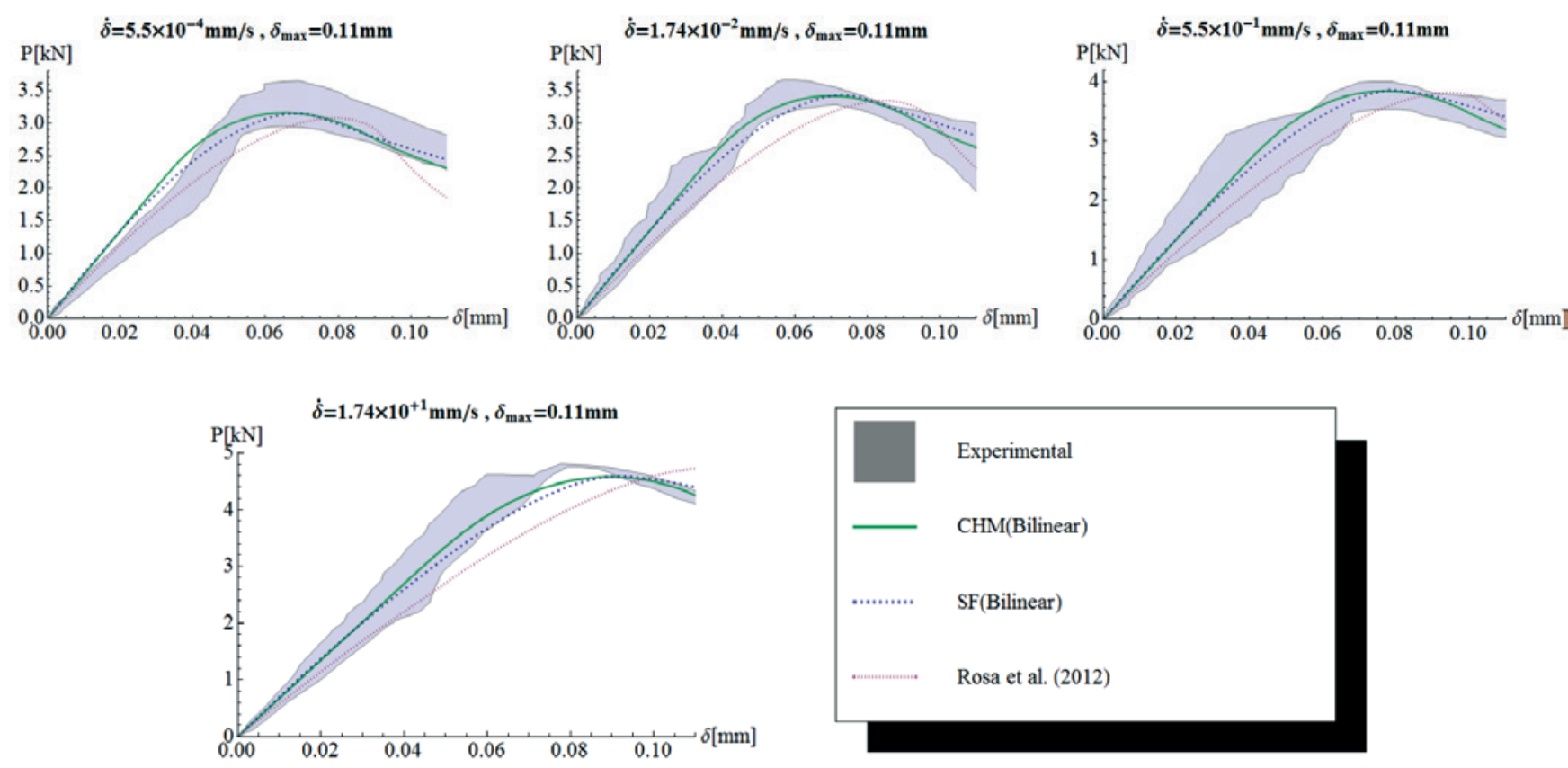

by [1] in the cohesive adjustment module of the developed computational tool. The cohesive fit module does not take into account the effects of loading rate, and the cohesive fit curve is a mathematical representation of an "average" cohesive curve. Thus, the intention is that the mathematical fitting evidences certain physical behaviours. The results obtained using the Hordijk's (1991) [33] cohesive curve with the numerical model CHM were chosen because of similar results from others models. Table 10 summarizes the results. As the table shows, $f_{t c}$ increases with the increase of actuator speed, which is in accordance with the formulation of [1].

Figure 25 shows the fitted curve and their respective cohesive curves. Figure 26 shows the overlap of the cohesive curves. Considering that an ideally brittle material is one whose cohesive curve has $w_{c}=0$, i.e., when reaching $f_{t c}$ the material breaks. Based on the observation above, it could be said that the lower $w_{c}$ is the closest it will be to a brittle material. Referring to Figure 26 and sustaining the above observation, the material becomes more brittle in the direction of $1.74 \times 10^{-5} \mathrm{~mm} / \mathrm{s}$ to $1.74 \times 10^{-2} \mathrm{~mm} / \mathrm{s}$ less fragile in $1.74 \times 10^{-2} \mathrm{~mm} / \mathrm{s}$ to $5.5 \times 10^{-1} \mathrm{~mm} / \mathrm{s}$ and then back again to becoming more fragile.

Thus, the model proposed by [1] apparently needs to consider a supplementation to account for the brittleness of the material with

\section{Table 6 - Results for the simultaneous fit of the viscous-cohesion using the cohesive model Hordijk (1991) (33)}

\begin{tabular}{|c|c|c|c|c|c|c|}
\hline Model & $\delta_{\max }(\mathrm{mm})$ & $\begin{array}{c}f_{\text {tc }} \\
(\mathrm{MPa})\end{array}$ & $\begin{array}{c}G_{F} \\
\left(J / m^{2}\right)\end{array}$ & $\dot{w}_{0}(\mathrm{~mm} / \mathrm{s})$ & $n$ & $\begin{array}{c}\text { Residue } \\
\left(\times 10^{-4}\right) \\
\left(\mathrm{kN}^{2} \cdot \mathrm{mm}\right)\end{array}$ \\
\hline \multirow{3}{*}{$\mathrm{CHM}$} & 0.450 & 5.13 & 63.7 & 6.92 & 0.105 & 9.68 \\
\hline & 0.225 & 4.83 & 62.6 & 2.33 & 0.101 & 3.95 \\
\hline & 0.110 & 4.31 & 87.9 & 1.01 & 0.127 & 0.84 \\
\hline \multirow{3}{*}{ SF } & 0.450 & 4.38 & 74.6 & 0.107 & 0.094 & 9.46 \\
\hline & 0.225 & 4.96 & 70.5 & 0.0468 & 0.107 & 4.46 \\
\hline & 0.110 & 5.01 & 64.3 & 0.0501 & 0.107 & 0.84 \\
\hline $\begin{array}{l}\text { Rosa et al. } \\
(2012)(1)\end{array}$ & 0.450 & 5.20 & 128 & 0.0965 & 0.16 & 41.40 \\
\hline
\end{tabular}


the increasing $f_{t c}$. Other types of viscous-cohesive curves presented in subsection 1 do not perform the observed behavior, even in the combination of model [1] with the model [24], this combination does not converge towards the expected result, since the latter increases the value of $w_{c}$ with the increasing loading rate.

The suggestion, after these observations, is to investigate a for- mulation that combines the fragility of the material with the loading rate and that complements the model [1].

\section{Conclusion}

The aim of this study is to evaluate the ability of the viscous-

Table 7 - Comparison of the results obtained by simultaneous fit of the Hordijk (1991) (33) cohesive model with the experimental data

\begin{tabular}{|c|c|c|c|c|c|}
\hline Model & $\delta_{\max }(\mathrm{mm})$ & $\begin{array}{c}f_{t c} \\
(M P a)\end{array}$ & $\begin{array}{l}P D f_{t c} \\
(M P a)\end{array}$ & $\begin{array}{c}G_{F}\left(G_{F(0-0.045)}\right) \\
\left(J / m^{2}\right)\end{array}$ & $\begin{array}{c}P D G_{F}\left(G_{F(0-0.45)}\right) \\
(\%)\end{array}$ \\
\hline Experimental & - & 5.20 & - & $123(95)$ & - \\
\hline \multirow{3}{*}{$\mathrm{CHM}$} & 0.450 & 5.13 & -1.35 & 63.7 & $-48.21(-32.95)$ \\
\hline & 0.225 & 4.83 & -7.12 & 62.6 & $-49.11(-34.11)$ \\
\hline & 0.110 & 4.31 & -17.12 & 87.9 & $-28.54(-7.47)$ \\
\hline \multirow{3}{*}{ SF } & 0.450 & 4.38 & -15.77 & 74.6 & $-39.35(-21.47)$ \\
\hline & 0.225 & 4.96 & -4.62 & 70.5 & $-42.68(-25.79)$ \\
\hline & 0.110 & 5.01 & -3.65 & 64.3 & $-47.72(-32.32)$ \\
\hline
\end{tabular}

Table 8 - Results of the simultaneous fit of the viscous-cohesion using the Bilinear cohesive model

\begin{tabular}{|c|c|c|c|c|c|c|c|c|c|}
\hline Model & $\begin{array}{c}\delta_{\max } \\
(\mathrm{mm})\end{array}$ & $\begin{array}{c}f_{\text {tc }} \\
(M P a)\end{array}$ & $\begin{array}{c}G_{F} \\
\left(J / m^{2}\right)\end{array}$ & $\begin{array}{c}a_{1} \\
\left(\mathrm{~mm}^{-1}\right)\end{array}$ & $\begin{array}{c}a_{2} \\
\left(\mathrm{~mm}^{-1}\right)\end{array}$ & $b_{2}$ & $\begin{array}{c}\dot{w}_{0} \\
(\mathrm{~mm} / \mathrm{s})\end{array}$ & $\mathrm{n}$ & $\begin{array}{c}\text { Residue } \\
\left(\times 10^{-4}\right) \\
\left(\mathrm{kN}^{2} \cdot \mathrm{mm}\right)\end{array}$ \\
\hline \multirow{3}{*}{$\mathrm{CHM}$} & 0.450 & 4.15 & 71.6 & 36.8 & 7.90 & 0.428 & 3.83 & 0.111 & 9.39 \\
\hline & 0.225 & 4.03 & 71.1 & 35.5 & 7.81 & 0.428 & 2.59 & 0.111 & 3.84 \\
\hline & 0.110 & 4.16 & 67.2 & 39.3 & 12.50 & 0.560 & 1.35 & 0.133 & 0.83 \\
\hline \multirow{3}{*}{ SF } & 0.450 & 4.73 & 74.5 & 57.8 & 3.27 & 0.266 & 0.0869 & 0.095 & 9.21 \\
\hline & 0.225 & 4.63 & 74.8 & 55.6 & 3.36 & 0.273 & 0.0855 & 0.097 & 3.80 \\
\hline & 0.110 & 4.48 & 122.7 & 52.1 & 0.452 & 0.135 & 0.106 & 0.132 & 1.03 \\
\hline $\begin{array}{l}\text { Rosa et al. } \\
(2012)(1)\end{array}$ & 0.450 & 5.20 & 128 & 50.0 & 0.43 & 0.12 & 0.0965 & 0.16 & 41.4 \\
\hline
\end{tabular}

\section{Table 9 - Comparison of the results of the simultaneous fit by Bilinear cohesive model with experimental data}

\begin{tabular}{|c|c|c|c|c|c|}
\hline Numerical model & $\begin{array}{l}\delta_{\max } \\
(\mathrm{mm})\end{array}$ & $\begin{array}{c}f_{t c} \\
(M P a)\end{array}$ & $\begin{array}{l}P D f_{t c} \\
(\%)\end{array}$ & $\begin{array}{c}G_{F}\left(G_{F(0-0.05)}\right) \\
\left(J / m^{2}\right)\end{array}$ & $\begin{array}{c}P D G_{F}\left(G_{F(0-0.45)}\right) \\
(\%)\end{array}$ \\
\hline Experimental & - & 5.20 & - & $123(95)$ & - \\
\hline \multirow{3}{*}{$\mathrm{CHM}$} & 0.450 & 4.15 & -20.19 & 71.6 & $-41.79(-24.63)$ \\
\hline & 0.225 & 4.03 & -22.50 & 71.1 & $-42.20(-25.16)$ \\
\hline & 0.110 & 4.16 & -20.00 & 67.2 & $-45.37(-29.26)$ \\
\hline \multirow{3}{*}{ SF } & 0.450 & 4.73 & -9.04 & 74.5 & $-39.43(-21.58)$ \\
\hline & 0.225 & 4.63 & -10.96 & 74.8 & $-39.19(-21.26)$ \\
\hline & 0.110 & 4.48 & -13.85 & 122.7 & $-0.24(-29.16)$ \\
\hline
\end{tabular}


cohesive model [1] to represent the behaviour of concrete under the influence of the loading rate using a computational tool for fit P- $\delta$ curves obtained in experiments with prismatic beams in three-point-bending tests. Thru the fitting it was possible to observe that the model is not able to completely represent the experimental data and that there is a large dependency on the adjustable interval. When simultaneous fitting is performed with viscous and cohesive model, the results do not reproduce the $f_{t c}$ and $G_{F}$ experimentally determined values. In section 5.6 a remark was made about the impact theory in which quasi-brittle materials behave as brittle with impact loads [34].

\section{Figure $19-\mathrm{P}-\delta$ curves for the range of 0 to $0.45 \mathrm{~mm}$ of simultaneously fit of Hordijk (1991) (33) and viscous model}
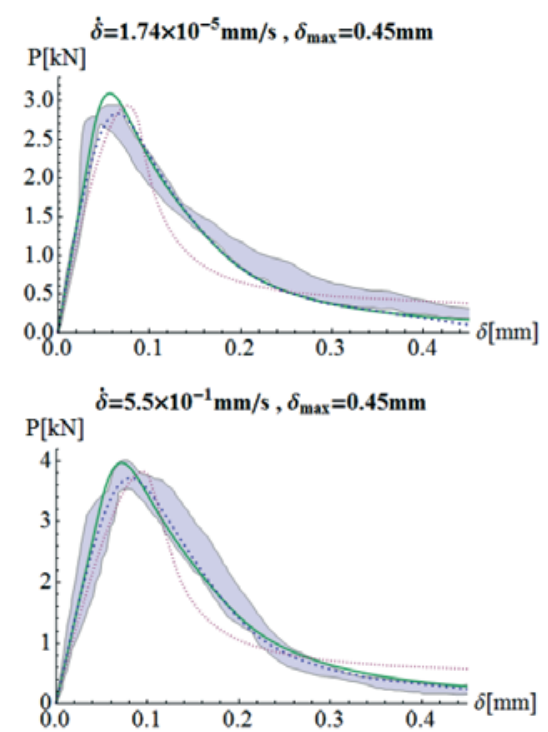
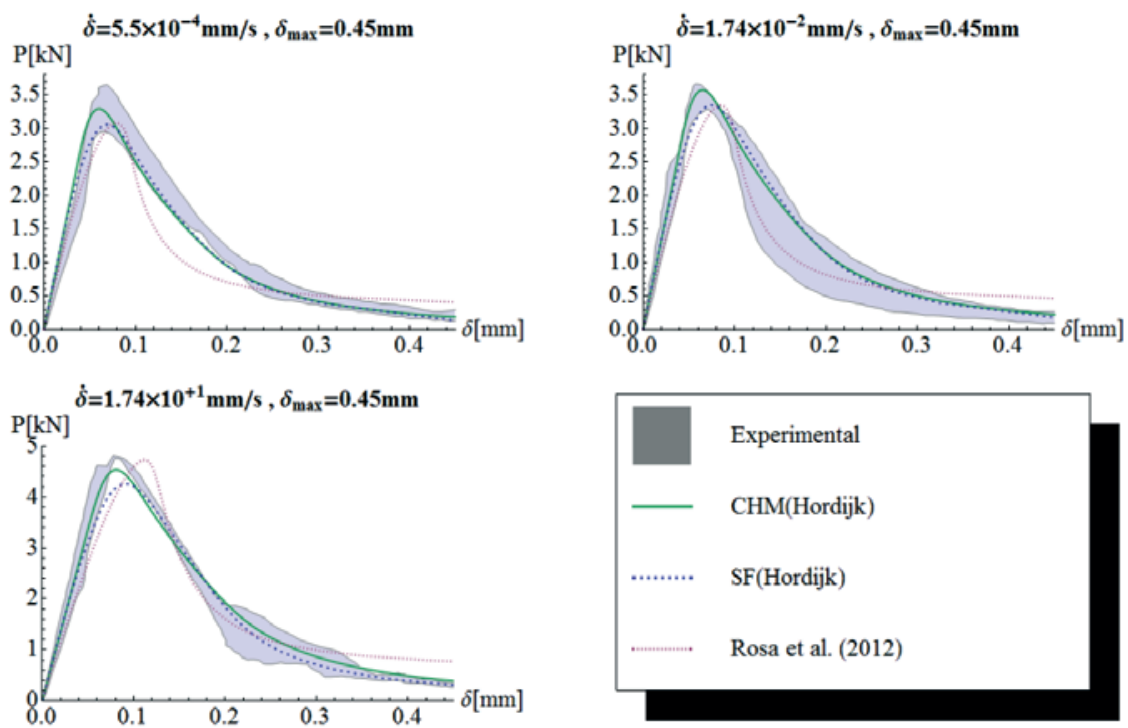

Figure $20-\mathrm{P}-\delta$ curves for the range of 0 to $0.225 \mathrm{~mm}$ of simultaneously fit of Hordijk (1991) (33) and viscous model
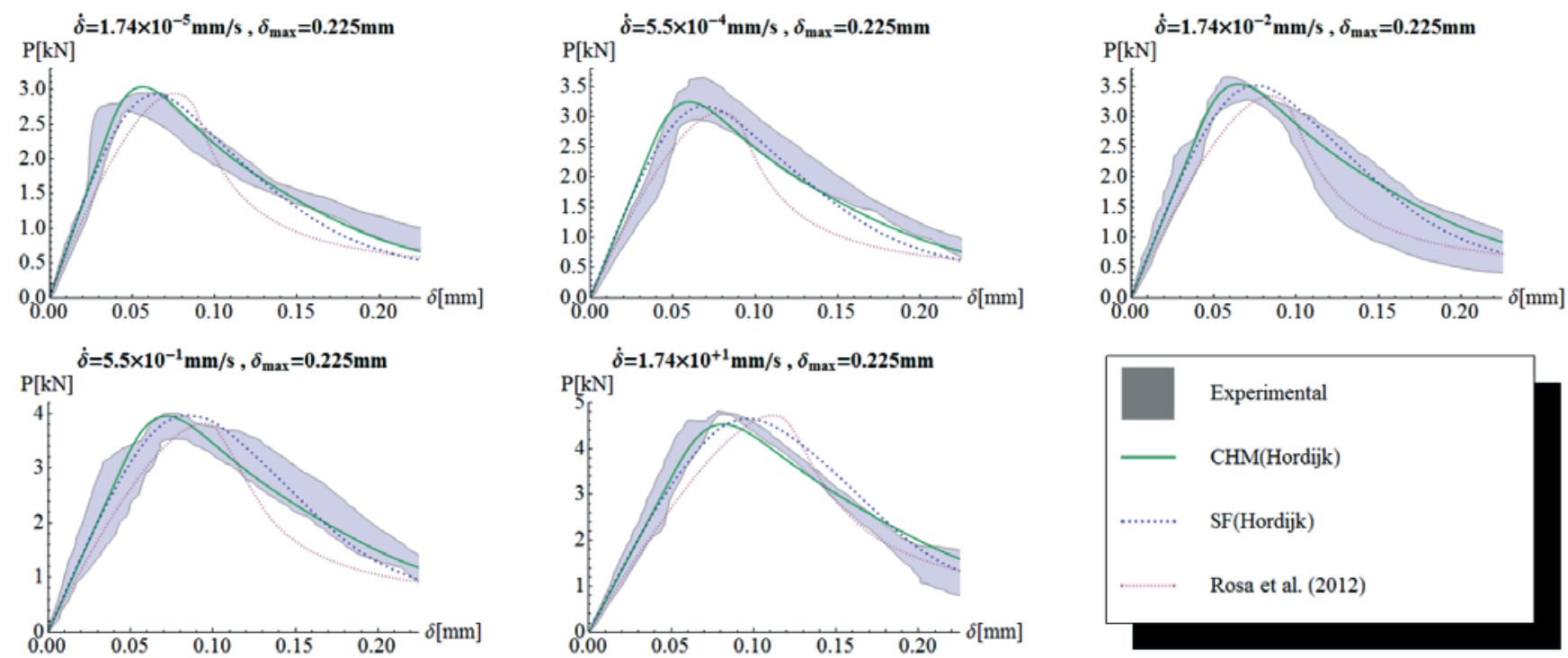
Searching for a connection between the quasi-brittle behavior and the behavior under impact conditions, it was observed that the material becomes more brittle with the increase of the loading rate.Thus it is suggested that a supplementation of the model [1] is necessary to account for the fragility of the material with increasing loading rate.

\section{Acknowledgements}

The authors thank Prof. Dr. Gonzalo Ruiz of Castilla-La Mancha University (UCLM) for making available the necessary experimental data for this study, Prof. Dr. Alaor Leandro Rosa, of the Faculty

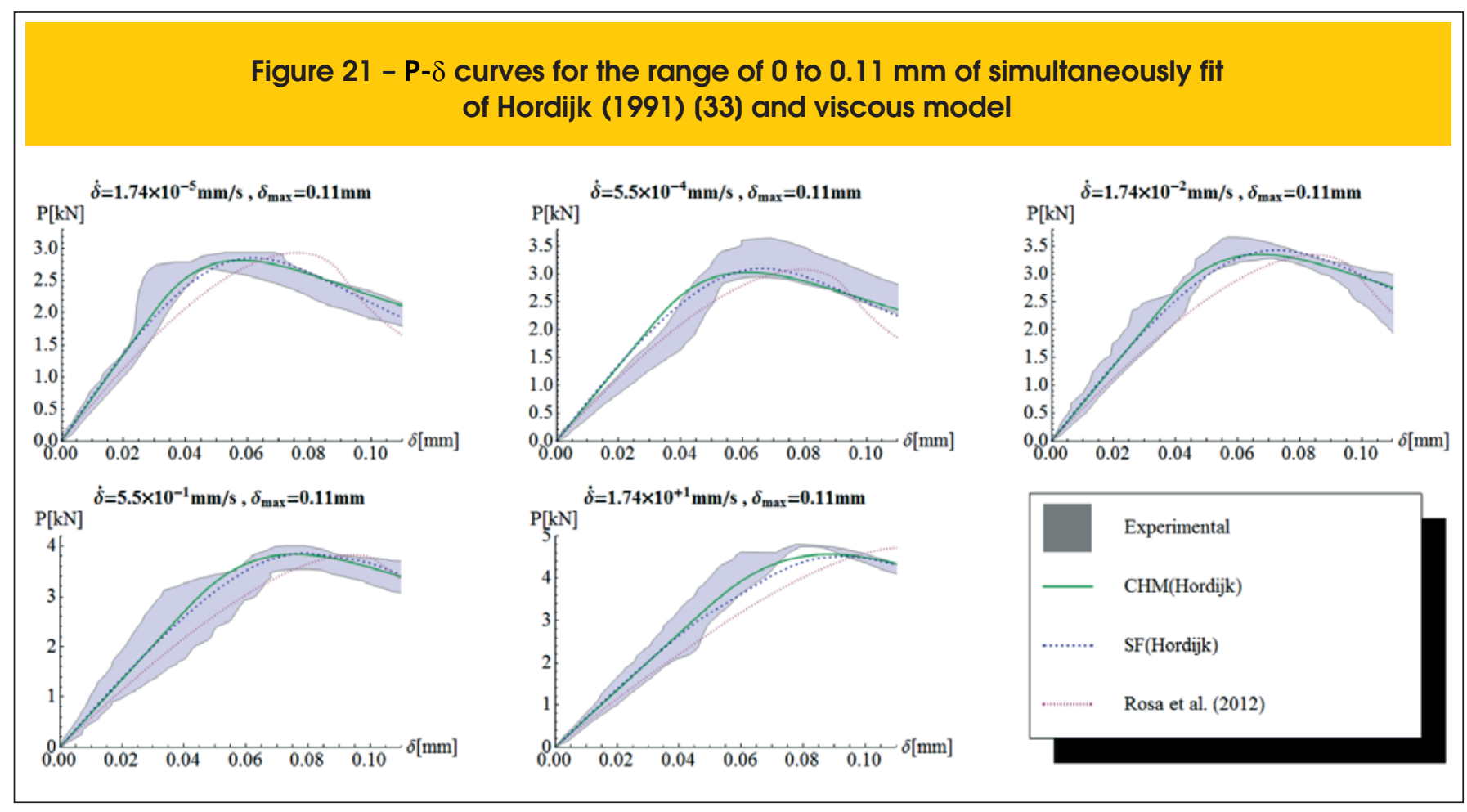

Figure 22 - P- $\delta$ curves for the range of 0 to $0.45 \mathrm{~mm}$ of simultaneously fit of bilinear and viscous model
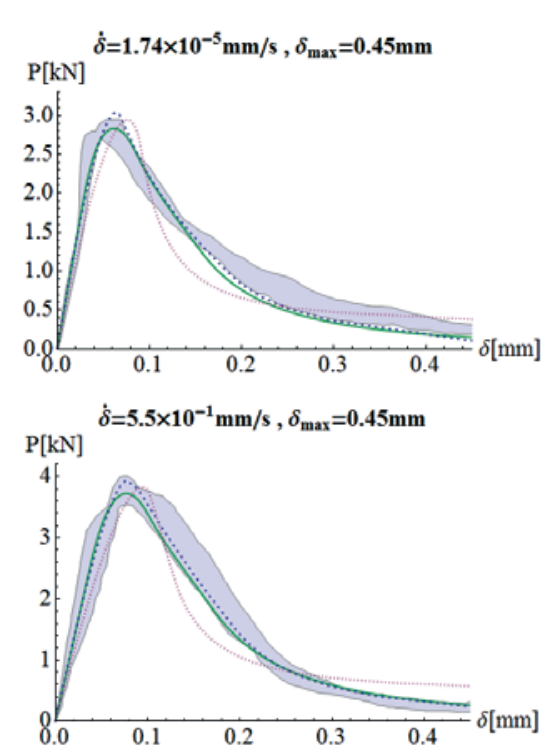
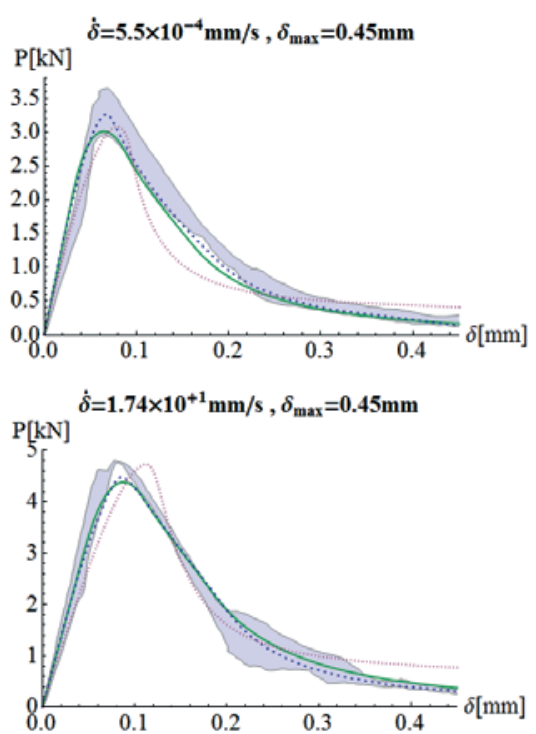
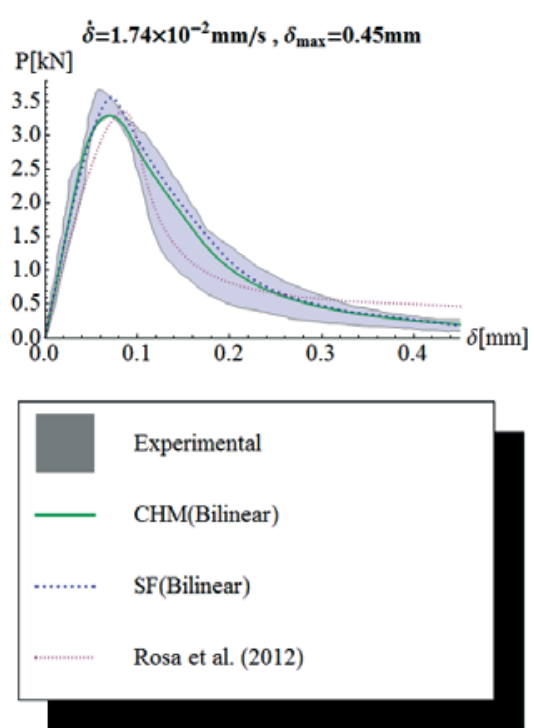
Determination of parameters of a viscous-cohesive fracture model by inverse analysis

Figure $23-\mathrm{P}-\delta$ curves for the range of 0 to $0.225 \mathrm{~mm}$ of simultaneously fit of bilinear and viscous model
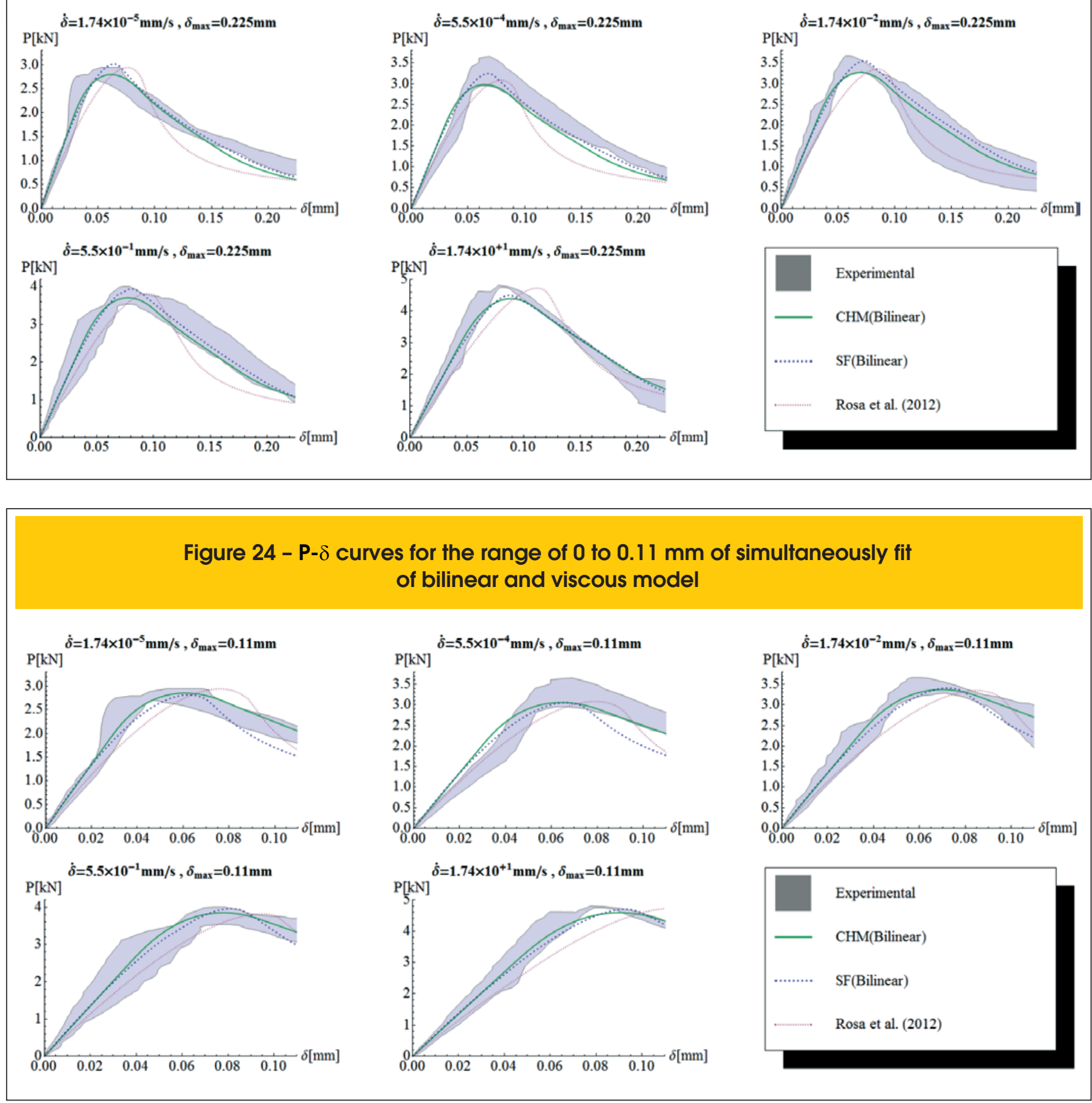

\begin{tabular}{|ccc|}
\hline \multicolumn{3}{|c|}{$\begin{array}{c}\text { Table 10 - Adjusting (33) cohesive curves } \\
\text { using CHM }\end{array}$} \\
\hline $\begin{array}{c}\text { Loading rate } \\
(\mathrm{mm} / \mathrm{s})\end{array}$ & $\begin{array}{c}f_{\mathrm{c}} \\
(\mathrm{MPa})\end{array}$ & $\begin{array}{c}\mathrm{G}_{\mathrm{F}} \\
\left(\mathrm{J} / \mathrm{m}^{2}\right)\end{array}$ \\
\hline $1.74 \times 10^{-5}$ & 5.03 & 98.0 \\
$5.5 \times 10^{-5}$ & 6.67 & 97.1 \\
$1.74 \times 10^{-5}$ & 7.37 & 79.0 \\
\hline $5.5 \times 10^{-5}$ & 8.14 & 96.3 \\
\hline $1.74 \times 10^{-5}$ & 10.5 & 109.0 \\
\hline
\end{tabular}


Figure 25 - Fit Hordijk (1991) (33) cohesive curve using the CHM for each experimental envelope
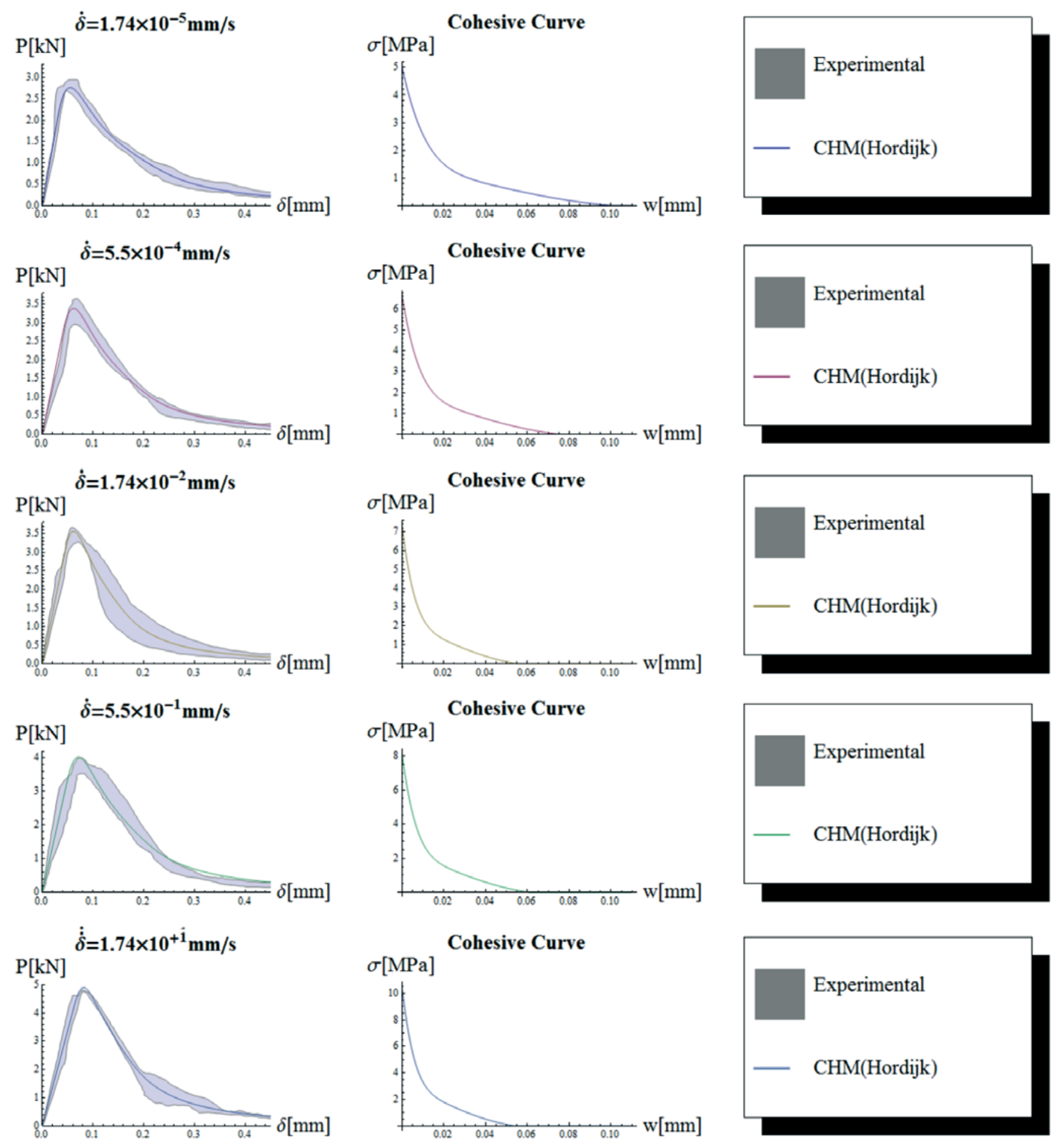

Experimental

CHM(Hordijk) 


\section{Figure 26 - Overlapping of fit cohesive curve}

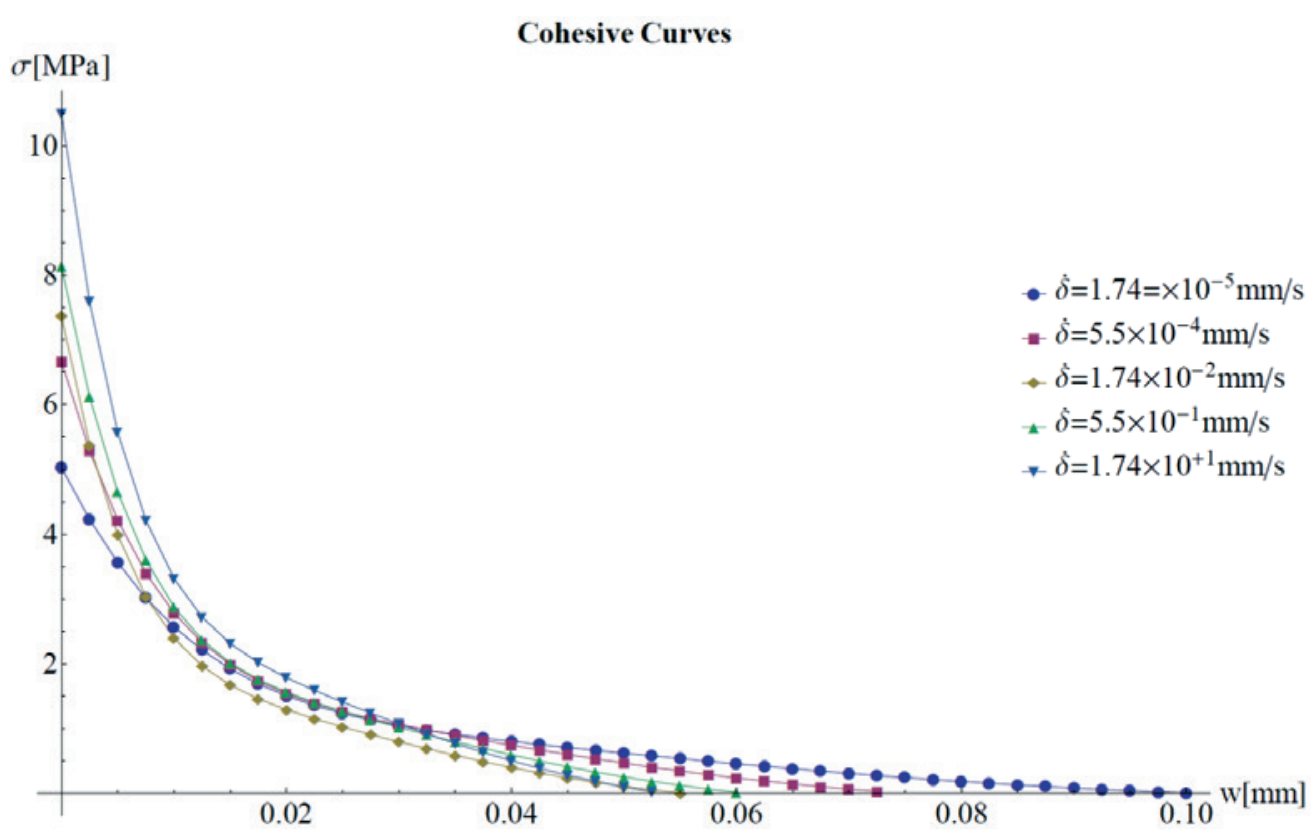

of Engineering of Sorocaba (FACENS), for his support and suggestions for this work.

\section{References}

[1] ROSA, A. L., YU, R. C., RUIZ, G., SAUCEDO, L., SOUSA, J. L. A. O. A loading rate dependent cohesive model for concrete fracture. Engineering Fracture Mechanics, v. 82, p.195208, 2012

[2] BARENBLATT, G. I. The formation of equilibrium cracks in brittle fracture. General ideas and hypothesis, axially symmetrical cracks. Journal of Applied Mathematics and Mechanics, v. 23, p.622-636, 1959.

[3] BARENBLATT, G. I. The mathematical theory of equilibrium cracks in brittle fracture. Advances in Applied Mechanics, v. 7, p.55-129, 1962.

[4] HILLERBORG, A., MODEER, M., PETERSSON, P. Analysis of crack formation and crack growth in concrete by means of fracture mechanics and finite elements. Cement and Concrete Research, v. 6, p.173-182, 1976.

[5] BAZANT, Z. P., OH, B. H. Crack band theory for fracture concrete. Materials and Structures, v. 16, n. 93, p.155-157, 1983.

[6] JENQ, Y. S., SHAH, S. P. Two-parameter fracture model for concrete. ASCE Journal of Engineering Mechanics, v. 111, $n$. 10, p.1227-1241, 1985.

[7] NALLATHAMBI, P., KARIHALOO, B. L. Determination of specimen size independent fracture toughness of plain concrete. Magazine of Concrete Research, v. 38, n. 135, p.67$76,1986$.
[8] TANG, T., OUYANG, C., SHAH, S. P. A simple method for determining material fracture parameters from peak loads. ACl Materials Journal, v. 93, n. 2, p.147-157, 1996.

[9] RÜSH, H. Research toward a General Flexural Theory for Structural Concrete. ACI Materials Journal, v. 57, p.1-28, 1960.

[10] AL-KUBAISY, M. A., YOUNG, A. G. Failure of concrete under sustained tension. Magazine of Concrete Research, v. 27, p.171-178, 1975.

[11] NISHIBAYASHI, S. Tensile creep of concrete. Proceedings of the 1978 RILEM Colloquium on Creep of Concrete. A.M. Neville and J.J. Brooks (Eds.), University of Leeds, England, p.274-287, 1978.

[12] GETTU, R., BAZANT, Z. P., KARR, M. E. Fracture properties and brittleness of high-strength concrete. $\mathrm{ACl}$ Materials Journal, v. 87, p.608-618, 1990.

[13] REINHARDT, H.W., WEERHEIJM, J. Tensile fracture of concrete at high loading rates taking into account of inertia and crack velocity effects. International Journal of Fracture, v. 51, p.31-42, 1991.

[14] ROSSI, P., VAN MIER, J. G. M., BOULAY, C., LE MAOU, F. The dynamic behaviour of concrete: influence of free water. Materials and Structures, v. 25, p.509-514, 1992.

[15] BAZANT, Z. P., GETTU, R. Rate effects and load relaxation in static fracture of concrete. ACl Materials Journal, v. 89, p.456-468, 1992.

[16] BAZANT, Z. P., JIRASEK, M. R-curve modelling of rate and size effects in quasi-brittle fracture. International Journal of Fracture, v. 62, p.355-373, 1993.

[17] ROSSI, P., VAN MIER, J. G. M., TOUTLEMONDE, F., LE 
MAOU, F., BOULAY, C. Effect of loading rate on the strength of concrete subjected to uniaxial tension. Materials and Structures, v. 27, p.260-264, 1994.

[18] BAZANT, Z. P., LI, Y. N. Cohesive crack with rate-dependent opening and visco-elasticity I: Mathematical model and scaling. International Journal of Fracture, v. 86, p.247-265, 1997.

[19] BAZANT, Z. P., CANER, F. C., ADLEY, M. D., AKERS, S. A. Fracturing rate effect and creep in microplane model for dynamics. Journal of Engineering Mechanics, v. 126, p.962970, 2000.

[20] BINDIGANAVILE, V., BANTHIA, N. Size effects and the dynamic response of plain concrete. Journal of Materials in Civil Engineering, v.18, p.485-491, 2006

[21] BRARA, A., KLEPACZCKO, J. R. Fracture energy of concrete at high loading rates in tension. International Journal of Impact Engineering, v. 34, p.424-435, 2007.

[22] WEERHEIJM, J., VAN DOORMAAL, J. Tensile fracture of concrete at high loading rates: new test data on strength and fracture energy from instrumented spalling tests. International Journal of Impact Engineering, v. 34, p.609-626, 2007.

[23] TANDON, S., FABER, K. T., BAZANT, Z. P., LI, Y. N. Cohesive crack modeling of influence of sudden changes in loading rate on concrete fracture. Engineering Fracture Mechanics, v. 52, n. 6, p.987-997, 1995.

[24] ZHOU, F., MOLINARI, J., SHIOYA, T. A rate-dependent cohesive model for simulating dynamic crack propagation in brittle materials. Engineering Fracture Mechanics, v.72, p.1383-1410, 2005.

[25] TARIFA, M., POVEDA, E., YU, R. C., ZHANG, X., RUIZ, G. Effect of loading rate on high-strength concrete: numerical simulations. VIII International Conference on Fracture Mechanics of Concrete and Concrete Structures, FraMCoS-8, 2013.

[26] GUINEA, G. V., PLANAS, J., ELICES, M. A general bilinear fit for the softening curve of concrete. Materials and Structures, v. 27, p.99-105, 1994

[27] SOUSA, J. L. A. O., GETTU, R. Determining the tensile stress-crack opening curve of concrete by inverse analysis. Journal of Engineering Mechanics, ASCE, v. 132, p.141-148, 2006.

[28] LEVENBERG, K. A method for the solution of certain nonlinear problems in least squares. Applied Mathematics, v. 2, p.164-168, 1944.

[29] MARQUARDT, D. An algorithm for least-squares estimation of nonlinear parameters. Journal of Applied Mathematics, v. 11, p.431-441, 1963.

[30] SOUSA, J. L. A. O. A Levenberg-Marquardt algorithm for fitting $\sigma-w$ curves from three-point-bend tests for plain and fiber reinforced concretes. Revista IBRACON de Estruturas e Materiais, v.4, n.4, p.691-694, 2011.

[31] OLESEN, J. F. Fictitious crack propagation in fiber-reinforced concrete beams. Journal of Engineering Mechanics, v. 127, n. 3, p.272-280, 2001.

[32] PLANAS, J., ELICES, M. A. Nonlinear fractures of cohesive materials. International Journal of Fractures, v. 51, p.139157, 1991.

[33] HORDIJK, D. A. Local approach to fatigue of concrete. Doctoral thesis, Delft University of Technology, The Netherlands, 1991.
[34] SANTOS, R. M. Comportamento de vigas de concreto armado reforçadas com CFC sujeitas a carga de impacto. Dissertação de Mestrado. Pontifícia Universidade Católica do Rio de Janeiro, 2008. 